\title{
A compromise programming approach for target setting in DEA
}

\author{
Sebastián Lozano $^{\mathrm{a} \S}$, Narges Soltani ${ }^{\mathrm{b}}$ and Akram Dehnokhalajic \\ ${ }^{a}$ Dept. of Industrial Management, University of Seville, Spain \\ ${ }^{\mathrm{b}}$ School of Information Technology, York University, Toronto, Canada \\ ${ }^{\mathrm{c}}$ Operations and Information Management Department, Aston Business School, \\ Aston University, Birmingham, B4 7ET, UK
}

\begin{abstract}
This paper presents a new Data Envelopment Analysis (DEA) target setting approach that uses the Compromise Programming (CP) method of multiobjective optimization. This method computes the ideal point associated to each Decision Making Unit (DMU) and determines an ambitious, efficient target that is as close as possible (using an $l_{\mathrm{p}}$ metric) to that ideal point. The specific cases $p=1, p=2$ and $p=\infty$ are separately discussed and analyzed. In particular, for $p=1$ and $p=\infty$, a lexicographic optimization approach is proposed in order to guarantee uniqueness of the obtained target. The original CP method is translation invariant and has been adapted so that the proposed CP-DEA is also units invariant. An $l_{\mathrm{p}}$ metric-based efficiency score is also defined for each DMU. The proposed CP-DEA approach can also be utilized in the presence of preference information, non-discretionary or integer variables and undesirable outputs. The proposed approach has been extensively compared with other DEA approaches on a dataset from the literature.
\end{abstract}

Keywords: Data Envelopment Analysis; target setting; compromise programming; ideal point; $l_{\mathrm{p}}$ metric

$\S$ Corresponding author:

Escuela Superior de Ingenieros

Camino de los Descubrimientos, s/n, 41092 Sevilla, Spain

(Phone: +34-954487208 E-mail: slozano@us.es) 


\section{Introduction}

Data envelopment analysis (DEA) is a non-parametric methodology generally used to assess the relative efficiency of a set of homogeneous Decision Making Units (DMUs) (Cooper et al. 2004, 2006). It is assumed that the inputs and outputs values for all units are explicitly known and the aim is to determine whether each unit is efficient or not. The latter corresponds to the case that the same (or more) outputs can be produced by consuming less inputs. The efficient DMUs are located on the efficient frontier, which corresponds to the best practice and the distance of a DMU to the efficient frontier is used to define an efficiency score.

Another key concept in DEA is the Production Possibility Set (PPS) which includes all technologically feasible operating points. This set is inferred from the observed DMUs using some standard axioms (like envelopment of the observed data, free disposability and convexity) together with the Minimum Extrapolation Principle. The efficient frontier is actually the nondominated subset of the PPS.

In addition to computing an efficiency score for each unit, DEA generally determines a target operating point on the efficient frontier. That target indicates the amount of input reduction and output increment that is required for the unit under evaluation to become efficient. Since the target is computed as a linear combination of some efficient DMUs, this information is useful for each unit to know its benchmarks (a.k.a. reference units). There are several DEA approaches for target setting, considering different orientations or projection directions and different ways of measuring the distance to the efficient frontier. Thus, DEA models that use Directional Distance Function (DDF) project an inefficient unit on a specific direction that can be exogenous or endogenous (e.g. Färe et al. 2013, Pastor et al. 2016, Wang et al. 2019, etc.). Another important class of DEA models aims at determining the closest efficient target (e.g. Aparicio et al. 2007, 2017, Aparicio 2016). Other methods follow the direction of the gradient of an efficiency potential function (Lozano and Calzada-Infante 2018), move towards the ideal point associated to the DMU (Asmild and Pastor 2010) or use some other criteria to determine the targets (e.g. Korhonen et al. 2018, Lee 2018).

As indicated above, most DEA approaches compute targets as a by-product of the efficiency measurement goal. However, proper DEA target setting should be approached from a 
multiobjective optimization perspective so that any Pareto efficient operating point dominating the DMU being projected can be selected as target. There are different multiobjective optimization techniques that can be used in this regard (see, for example, Marler and Arora 2004). Some of those techniques involve an interactive articulation of preferences (which requires a complex iterative process and a great deal of involvement by the DMU) or a posteriori articulation of preferences (which may produce cognitive stress on the DMU and requires visual aids to aid the DM in the target selection step). Compromise Programming (CP), on the other hand, does not require preference information (although it can incorporate it in the form of weights) and is therefore a simple and effective multiobjective optimization method. In addition it has a fine graphical interpretation that can be used to explain how it works. This makes this technique particularly fitting for the DEA target setting task considered.

Hence, in this paper a CP DEA target setting approach is proposed. CP is a multiobjective optimization method that dates back to Yu (1973) (see also Freimer and Yu 1976) and is also known as the Yu family solution of bargaining problems (Thomson 1994). The method computes the closest target (using $l_{\mathrm{p}}$ metric) to the ideal point. This ideal point must be previously computed and, as its name suggests, it is not achievable in general. Parameter $p$ can take values $p \in[1, \infty)$ with values $p=1, p=2$ and $p=\infty$ singled out, corresponding to rectangular, Euclidean and Tchebycheff distances, respectively. The value $p=\infty$ is also known as MinMax or Tchebycheff approach. The CP model is known to be translation invariant and to lead to a Pareto optimal solution for $1 \leq p<\infty$, with the solution being unique for $1<p<\infty$ (Yu 1973).

The proposed approach radically differs from traditional DEA target setting in the point of view adopted. Thus, most methods look at the efficient frontier from inside the PPS. They use the observed DMU as home base and measure input and output improvements with respect to the current situation. However, consistent with its $\mathrm{CP}$ character, the proposed target setting approach computes an ideal point which represents the maximum aspiration levels along the different input and output dimensions. This ideal point is generally infeasible (i.e. too ambitious) but can be used as reference so as to try to get as close to this ideal point as possible. Therefore, in CP-DEA the perspective is from outside the PPS and the targets computed are as ambitious as they can get. 
The structure of this paper is as follows. Section 2 reviews the implementation of the CP method in DEA. Section 3 presents and discusses the proposed CP-DEA approach. Section 4 provides a numerical example to illustrate the proposed approach. Section 5 compares the proposed approach with different DEA approaches using a dataset from the literature. Finally, the paper is concluded in section 6 with some further research outlined.

\section{Literature review}

$\mathrm{CP}$ has been used before in DEA but not for target setting. Almost all existing DEA CP approaches use a multiplier formulation to compute a common set of weights (CSW) (e.g. Despotis 2002, Hashimoto and Wu 2004, Kao and Hung 2005, Zohrehbandian et al. 2010, etc). This type of approaches assumes that the multiple objective functions to maximize are the efficiencies of the DMUs and considers either $(1,1, \ldots, 1)$ or the vector formed with individual DMUs' efficiency scores (denoted by $\boldsymbol{\theta}^{C C R}$ ) as the ideal point. Some methods also use $(0,0, \ldots, 0)$ as an anti-ideal point. Table 1 provides a classification of such methods. The table also includes other closely related DEA approaches which, without being labeled CP, are closely related (e.g. Roll and Golany 1993, Hosseinzadeh Lofti et al. 2000, Cook and Zhu 2007, Wang et al. 2011a, Davoodi and Rezai 2012).

Table 1

Table 2 reports the different mathematical formulations in DEA CP literature. Constant Returns to Scale (CRS) are assumed for the production technology in all formulations. A major difference between our proposed CP-DEA approach and the existing DEA CP methods is that CP-DEA is based on envelopment forms and aims at target setting instead of ranking DMUs. Except when indicated otherwise, in all models of Table 2, we assume that 


$$
\begin{gathered}
E_{j}=\frac{\sum_{k} v_{k} y_{k j}}{\sum_{i} u_{i} x_{i j}} \forall j \\
u_{i} \geq \varepsilon \quad \forall i \quad v_{k} \geq \varepsilon \quad \forall k
\end{gathered}
$$

where DMU j consumes $x_{i j}$ value of input $\mathrm{i}$ to produce $y_{k j}$ value of output $\mathrm{k}$ for all $j=1,2, \ldots, n$, $i=1,2, \ldots, m$ and $k=1,2, \ldots, s, \varepsilon>0$ is non-Archimedean, $u_{i}$ and $v_{k}$ are the (common set of weight) shadow prices of input $\mathrm{i}$ and output $\mathrm{k}$, respectively for all $i=1,2, \ldots, m$ and $k=1,2, \ldots, s$. Also $E_{j}$ is the Common Set of Weights (CSW) efficiency score and $\theta_{j}^{C C R}$ is the efficiency score 'under the best possible light' for DMU j. In addition, $\boldsymbol{\theta}^{C C R}=\left(\theta_{1}^{C C R}, \theta_{2}^{C C R}, \ldots, \theta_{n}^{C C R}\right)$ denotes the vector of individual DMUs' efficiency scores.

A somewhat different CSW DEA CP approach was proposed by Kao (2010) for ranking alternatives in a MCDM context. Kao (2010) considers a pure output DEA model and assumes an ideal point defined by the best observed value among DMUs, i.e., $y_{k}^{\max }=\max _{j} y_{k j}$, and an antiideal point given by $y_{k}^{\text {min }}=\min _{j} y_{k j}$. Also, Carrillo and Jorge (2016) proposed a CSW DEA CP approach for ranking alternatives in a MCDM context. The two objective functions they consider are minimizing the virtual input and maximizing the virtual output.

The parameter $p$ in $\mathrm{CP}$ represents the importance given to the computation of the $l_{p}$ distance to the maximum regret. For $p=1$, the maximum regret is considered as important as all other regrets and $\mathrm{CP}$ minimizes the sum of the regrets (i.e. the average regret). On the contrary, for $p=\infty$, the maximum regret is the only one that matters and $\mathrm{CP}$ minimizes the maximum regret. For $1<p<\infty$, we have all intermediate cases among those two extremes. For $1 \leq p<\infty$, the solution is guaranteed to be Pareto optimal while for $p=\infty$ only weak Pareto optimality is guaranteed. Uniqueness is only guaranteed when $1<p<\infty$. Finally, when the constraints are linear as 
generally they are in DEA, the resulting optimization model is Linear Programming (LP) only for $p=1$ and $p=\infty$.

Zohrehbandian et al. (2010) only considered the cases, $p=1$ and $p=\infty$, and they obtained LP formulations. Same happens in the work of Carrillo and Jorge (2016). Despotis (2002) considered a convex linear combination of $p=1$ and $p=\infty$ distances as the objective function. Hashimoto and Wu (2004) only considered the values $p=1, p=2$ and $p=\infty$ and recommended $p=2$ due to the uniqueness of the solution. Kao and Hung (2005) claimed that $p=1$ and $p=\infty$ are not good choices because they may produce alternative solutions, but $p=2$, which compromises among the regrets "in an statistical sense", is probably the most appropriate assumption. For $p=\infty$, they considered the classical scalarizing function that utilizes the $l_{1}$ distance in order to guarantee Pareto optimality and to discriminate among the closest solutions computed applying $l_{\infty}$. Note that their proposed scalarizing function is equivalent to the augmented Tchebycheff method. This method, together with the modified and lexicographic Tchebycheff methods, have been applied in different multiobjective DEA approaches (e.g. Chen et al. 2009, Despotis et al. 2016).

Kao (2010) studied two different CSW DEA CP approaches, one based on the absolute weighted distance to the ideal point and the other based on the relative distance to both the ideal and antiideal points. In the first case, $p=2$ is considered and the solution is obtained analytically using Lagrange's method. For the relative distance model, $p=1$ is assumed to compute the distances but then the objective function minimizes the square of those $l_{1}$ distances (summed for all DMUs).

The final remark is that there are many DEA approaches (e.g. Wang and Luo 2006, Wang et al. 2011b, Sun et al. 2013) that define and utilize an ideal DMU $\left(x^{\min }, y^{\max }\right)=$ $\left(x_{1}^{\min }, x_{2}^{\text {min }}, \ldots, x_{m}^{\text {min }}, y_{1}^{\text {max }}, y_{2}^{\max }, \ldots, y_{s}^{\text {max }}\right)$ with coordinates $x_{i}^{\text {min }}=\min _{j} x_{i j}$ and $y_{k}^{\text {max }}=\max _{j} y_{k j}$. This should not be confused with the ideal point $\left(x_{0}^{\min }, y_{0}^{\max }\right)$ in our method (or in MEA, for that matter), which is specific for each DMU 0 and requires, as it can be seen in the next section, solving $(m+s)$ LP models, one for each input and output index. 
Apart from the existing DEA CP approaches reviewed above, it is relevant to mention the Multidirectional Efficiency Analysis (MEA) proposed by Asmild and Pastor (2010) which computes the target using two phases. Phase I consists of moving along the direction from the DMU being projected to its associated ideal point. Thus, the target is computed moving away from the observed DMU towards the efficient frontier. The proposed CP-DEA approach, however, computes the target from outside, looking for the closest feasible point to the ideal point. In this regard, the proposed CP-DEA approach is more similar to other outside-projection approaches, based on the weighted Tchebycheff method, that can be used to sample the whole efficient frontier by varying the weight vector (e.g. Gutiérrez and Lozano 2016) or in an interactive DEA MOLP fashion (e.g. Ebrahimnejad and Tavana 2014, Tavana et al. 2018).

\section{Our proposed CP-DEA approach}

First of all, we normalize the observed input and output data using the standard deviation of the corresponding input or output variable. The normalized (and dimensionless) input and output values are computed as

$$
\hat{x}_{i j}=\frac{x_{i j}}{\sigma_{i}^{x}} \forall i \forall j \quad, \quad \hat{y}_{k j}=\frac{y_{k j}}{\sigma_{k}^{y}} \forall k \forall j
$$

Now, we define the dimensionless PPS for the Variable Returns to Scale (VRS) case as follows:

$$
T^{V R S}=\left\{(\hat{x}, \hat{y}) \mid \hat{x} \geq \hat{X} \lambda, \hat{y} \leq \hat{Y} \lambda, e^{t} \lambda=1, \lambda \geq 0\right\}
$$

It is clear that $T^{V R S}$ has a one-to-one correspondence with the original VRS PPS

$$
T^{V R S}=\left\{(x, y) \mid x \geq X \lambda, y \leq Y \lambda, e^{t} \lambda=1, \lambda \geq 0\right\}
$$

This specific normalization allows the proposed CP-DEA approach to be units invariant and, in the VRS case, also translation invariant. Note, in this regard, that since the CP method is based on the $l_{p}$ distance, it is translation invariant. 
In order to project a certain DMU 0 onto the efficient frontier, we must compute its associated dimensionless ideal point $\left(\hat{x}_{0}^{\min }, \hat{y}_{0}^{\max }\right)=\left(\hat{x}_{10}^{\min }, \hat{x}_{20}^{\min }, \ldots, \hat{x}_{m 0}^{\min }, \hat{y}_{10}^{\max }, \hat{y}_{20}^{\max }, \ldots, \hat{y}_{s 0}^{\max }\right) \quad$ whose coordinates are obtained by solving the corresponding LP models for each input $i$ and each output $k$, which aim at improving each input and output dimension in turn as much as possible. The following models compute the input and output entries of the ideal point respectively:

$\hat{x}_{i 0}^{\min }=\operatorname{Min} \hat{x}_{i}$

s.t.

$\sum_{j} \lambda_{j} \hat{x}_{i^{\prime} j} \leq \hat{x}_{i^{\prime} 0} \quad \forall i^{\prime} \neq i$

$\sum_{j} \lambda_{j} \hat{x}_{i j} \leq \hat{x}_{i}$

$\sum_{j} \lambda_{j} \hat{y}_{k j} \geq \hat{y}_{k 0} \quad \forall k$

$\sum_{j} \lambda_{j}=1$

$\lambda_{j} \geq 0 \forall j \quad \hat{x}_{i}$ free $\hat{y}_{k 0}^{\max }=\operatorname{Max} \quad \hat{y}_{k}$

s.t.

$\sum_{j} \lambda_{j} \hat{x}_{i j} \leq \hat{x}_{i 0} \quad \forall i$

$\sum_{j} \lambda_{j} \hat{y}_{k^{\prime} j} \geq \hat{y}_{k^{\prime} 0} \quad \forall k^{\prime} \neq k$

$\sum_{j} \lambda_{j} \hat{y}_{k j} \geq \hat{y}_{k}$

$\sum_{j} \lambda_{j}=1$

$\lambda_{j} \geq 0 \forall j \quad \hat{y}_{k}$ free

The above models are analogous to the ones used in the MEA approach of Asmild and Pastor (2010) except that they are formulated on the dimensionless input and output variables. However, while MEA uses a DDF approach that projects DMU 0 along the direction from that unit to its associated ideal point, the proposed CP-DEA approach considers a reverse projection and looks at the PPS from outside, minimizing the distance from the ideal point to the PPS, i.e. projecting the ideal point onto the PPS frontier. This idea has a nice graphical interpretation where different iso-distance curves of the objective function are depicted starting from the dimensionless ideal point increasingly until one of them is tangent to the subset of the dimensionless PPS that dominates DMU 0. Actually, the point of tangency is the obtained target, as it is the closest feasible point (among those that dominate DMU 0) to the dimensionless ideal point of DMU 0.

Therefore, the proposed CP-DEA model can be formulated as 
$\operatorname{Min}\left\|(\hat{x}, \hat{y})-\left(\hat{x}_{0}^{\min }, \hat{y}_{0}^{\max }\right)\right\|_{p}$

s.t.

$\sum_{j} \lambda_{j} \hat{x}_{i^{\prime} j} \leq \hat{x}_{i} \leq \hat{x}_{i 0} \quad \forall i$

$\sum_{j} \lambda_{j} \hat{y}_{k j} \geq \hat{y}_{k} \geq \hat{y}_{k 0} \quad \forall k$

$\sum_{j} \lambda_{j}=1$

$\lambda_{j} \geq 0 \forall j \quad \hat{x}_{i}$ free $\forall i \quad \hat{y}_{k}$ free $\forall k$

Let $1 \leq p<\infty$. According to the definition of $l_{p}$ metric, we have

$$
\begin{aligned}
\left\|(\hat{x}, \hat{y})-\left(\hat{x}_{0}^{\text {min }}, \hat{y}_{0}^{\text {max }}\right)\right\|_{p} & =\left[\sum_{i}\left|\hat{x}_{i}-\hat{x}_{i 0}^{\text {min }}\right|^{p}+\sum_{k}\left|\hat{y}_{k}-\hat{y}_{k 0}^{\max }\right|^{p}\right]^{1 / p}= \\
& =\left[\sum_{i}\left(\hat{x}_{i}-\hat{x}_{i 0}^{\text {min }}\right)^{p}+\sum_{k}\left(\hat{y}_{k 0}^{\text {max }}-\hat{y}_{k}\right)^{p}\right]^{1 / p}
\end{aligned}
$$

Since the power function is monotonic, the $1 / p$ exponent can be omitted from the corresponding objective function of model (7). For $p=\infty$, we have

$$
\begin{aligned}
\left\|(\hat{x}, \hat{y})-\left(\hat{x}_{0}^{\min }, \hat{y}_{0}^{\max }\right)\right\|_{\infty} & =\max \left\{\max _{i}\left|\hat{x}_{i}-\hat{x}_{i 0}^{\min }\right|, \max _{k}\left|\hat{y}_{k}-\hat{y}_{k 0}^{\max }\right|\right\}= \\
& =\max \left\{\max _{i}\left(\hat{x}_{i}-\hat{x}_{i 0}^{\min }\right), \max _{k}\left(\hat{y}_{k 0}^{\max }-\hat{y}_{k}\right)\right\}
\end{aligned}
$$

In all cases, the target unit corresponding to the dimensionless target point computed by above model (7) can be recovered as

$$
x_{i}=\hat{x}_{i} \cdot \sigma_{i}^{x} \forall i \quad, \quad y_{k}=\hat{y}_{k} \cdot \sigma_{k}^{y} \forall k
$$


Let us consider each of the three typical values for parameter $p$, starting with $p=2$. In that case, model (7) involves a quadratic programming (QP) problem, with the objective function

$$
\operatorname{Min} \sum_{i}\left(\hat{x}_{i}-\hat{x}_{i 0}^{\min }\right)^{2}+\sum_{k}\left(\hat{y}_{k 0}^{\max }-\hat{y}_{k}\right)^{2}
$$

For $p=1$ the objective function of model (7) becomes

$$
\operatorname{Min} \sum_{i}\left(\hat{x}_{i}-\hat{x}_{i 0}^{\min }\right)+\sum_{k}\left(\hat{y}_{k 0}^{\max }-\hat{y}_{k}\right)
$$

and can be simply rewritten as

$$
\operatorname{Min} \sum_{i} \hat{x}_{i}-\sum_{k} \hat{y}_{k}
$$

Hence, the resulting model can be shown to be equivalent to the classical additive DEA model. The CP-DEA perspective, however, is different and, for example, allows us to realize that this model may have alternative optima, which means the target is not uniquely determined. This defect appears in the classical additive DEA model (and in other slacks-based DEA models like the Range Adjusted Measure of efficiency, RAM, of Cooper et al. 1999 or the Slacks-based Inefficiency SBI model of Fukuyama and Weber 2009) and it is generally neglected and ignored. The issue of alternative targets is more widespread than it is acknowledged, for example, in the classical radial BCC DEA model of Banker et al. (1984) where the target is determined by the slacks maximization in phase II, which in fact uses a rectangular metric. The solution we propose to uniquely determine the CP-DEA target for the $p=1$ case is a lexicographic optimization approach that uses the $p=2$ distance to select among the possible alternative optima of (13), i.e.

$$
\operatorname{Lex} \operatorname{Min}\left\{\left\|(\hat{x}, \hat{y})-\left(\hat{x}_{0}^{\min }, \hat{y}_{0}^{\text {max }}\right)\right\|_{1},\left\|(\hat{x}, \hat{y})-\left(\hat{x}_{0}^{\text {min }}, \hat{y}_{0}^{\text {max }}\right)\right\|_{2}\right\}
$$


Since for $p=2$ the solution is guaranteed to be unique, this seems to be a simple and reasonable way of breaking ties and selecting among the closest $l_{1}$ targets. Note that the $p=2$ objective function involves QP. However, that step is not necessary if there are no alternative optima for $p=1$, which can be ascertained from the optimal dual solution for $p=1$ checking whether any dual variable is zero.

For $p=\infty$, we have a similar scenario where the solution of model (7) may not be unique. Therefore we propose using a similar lexicographic optimization approach. i.e.

$$
\operatorname{Lex} \operatorname{Min}\left\{\left\|(\hat{x}, \hat{y})-\left(\hat{x}_{0}^{\min }, \hat{y}_{0}^{\max }\right)\right\|_{\infty},\left\|(\hat{x}, \hat{y})-\left(\hat{x}_{0}^{\min }, \hat{y}_{0}^{\max }\right)\right\|_{2}\right\}
$$

As before, the $p=2$ objective function, whose aim is to select among the closest $l_{2}$ targets is only necessary if there are alternative optima for $p=\infty$, which can be ascertained from the corresponding optimal dual solution.

Therefore, the proposed CP-DEA approach, (with the lexicographic enhancements commented above for $p=1$ and $p=\infty)$, can compute an efficient and unique target $\left(\hat{x}^{*}, \hat{y}^{*}\right)$. We address now the question of computing an efficiency score for DMU 0 based on the target obtained above.

Definition 1. The CP-DEA efficiency score is defined as

$$
\xi_{0}^{p}=\frac{1}{1+\left\|\left(\hat{x}^{*}, \hat{y}^{*}\right)-\left(\hat{x}_{0}, \hat{y}_{0}\right)\right\|_{p}}
$$

where $\left(\hat{x}^{*}, \hat{y}^{*}\right)$ is the obtained target unit from the CP-DEA model.

It is clear that $0 \leq \xi_{0}^{p} \leq 1$. Moreover, $\xi_{0}^{p}=1$ if and only if $\left(\hat{x}^{*}, \hat{y}^{*}\right)=\left(\hat{x}_{0}, \hat{y}_{0}\right)$, or, equivalently, if DMU 0 is projected onto itself. Since the computed target is always efficient, that can only happen if DMU 0 is efficient. 
Note that although the simple $l_{p}$ norm has been applied above, in case that there are some preference information for the data, the weighted $l_{p}$ distance can be used (Yu 1973) correspondingly. Thus, given a vector of strictly positive weights $\left(w_{i}^{x}, w_{k}^{y}\right)$ with the property that $\sum_{i=1}^{m} w_{i}^{x}+\sum_{k=1}^{s} w_{k}^{y}=1$, the corresponding weighted $l_{p}$ distances for the objective function of model (7) can be considered as follows:

$$
\begin{array}{ll}
\left\|(\hat{x}, \hat{y})-\left(\hat{x}_{0}^{\min }, \hat{y}_{0}^{\max }\right)\right\|_{p, w}=\left\{\sum_{i}\left[w_{i}^{x} \cdot\left(\hat{x}_{i}-\hat{x}_{i 0}^{\min }\right)\right]^{p}+\sum_{k}\left[w_{k}^{y} \cdot\left(\hat{y}_{k 0}^{\max }-\hat{y}_{k}\right)\right]^{p}\right\}^{1 / p} & \text { for } 1 \leq p<\infty \\
\left\|(\hat{x}, \hat{y})-\left(\hat{x}_{0}^{\min }, \hat{y}_{0}^{\max }\right)\right\|_{\infty, w}=\max \left\{\max _{i}\left[w_{i}^{x} \cdot\left(\hat{x}_{i}-\hat{x}_{i 0}^{\min }\right)\right], \max _{k}\left[w_{k}^{y} \cdot\left(\hat{y}_{k 0}^{\max }-\hat{y}_{k}\right)\right]\right\} & \text { for } p=\infty
\end{array}
$$

Also, the following distances are used in equation (16) to define the efficiency scores, correspondingly:

$$
\begin{array}{ll}
\left\|\left(\hat{x}^{*}, \hat{y}^{*}\right)-\left(\hat{x}_{0}, \hat{y}_{0}\right)\right\|_{p, w} & =\left\{\sum_{i}\left[w_{i}^{x} \cdot\left(\hat{x}_{i 0}-\hat{x}_{i}^{*}\right)\right]^{p}+\sum_{k}\left[w_{k}^{y} \cdot\left(\hat{y}_{k}^{*}-\hat{y}_{k 0}\right)\right]^{p}\right\}^{1 / p} \quad \text { for } 1 \leq p<\infty \\
\left\|\left(\hat{x}^{*}, \hat{y}^{*}\right)-\left(\hat{x}_{0}, \hat{y}_{0}\right)\right\|_{\infty, w} & =\max \left\{\max _{i}\left[w_{i}^{x} \cdot\left(\hat{x}_{i 0}-\hat{x}_{i}^{*}\right)\right], \max _{k}\left[w_{k}^{y} \cdot\left(\hat{y}_{k}^{*}-\hat{y}_{k 0}\right)\right]\right\}
\end{array}
$$

Note that assigning different weights to different inputs and outputs affects the targets and the efficiency scores, favoring improvements along the more important dimensions and weighing the corresponding slacks (i.e. inefficiencies) more. The graphical interpretation of the weighted CPDEA scenario leads to changes in the iso-distance curves' shape which, for example, for $\mathrm{p}=2$ are no longer circles but ellipses.

Our proposed CP DEA approach can also be used when some of the variables are nondiscretionary following Banker and Morey (1986). Thus, let $I^{D}$ and $I^{N D}$ be the index sets of discretionary and non-discretionary inputs and $O^{D}$ and $O^{N D}$ be the index sets of discretionary and non-discretionary outputs. For the non discretionary inputs and outputs it is not necessary to solve models (5) and (6) to obtain $\hat{x}_{i 0}^{\min }$ and $\hat{y}_{k 0}^{\max }$ since the components of the ideal point for those variables are, by definition, equal to the corresponding components of DMU 0, i.e. 
$x_{i 0}^{\min }=x_{i 0} \forall i \in I^{N D}, y_{k 0}^{\max }=y_{k 0} \forall k \in O^{N D}$. Therefore, the corresponding CP-DEA model can be written as

$$
\operatorname{Min}\left\|(\hat{x}, \hat{y})-\left(\hat{x}_{0}^{\min }, \hat{y}_{0}^{\max }\right)\right\|_{p}
$$

s.t.

$$
\begin{aligned}
& \sum_{j} \lambda_{j} \hat{x}_{i^{\prime} j} \leq \hat{x}_{i} \leq \hat{x}_{i 0} \quad \forall i \in I^{D} \\
& \sum_{j} \lambda_{j} \hat{x}_{i^{\prime} j} \leq \hat{x}_{i}=\hat{x}_{i 0} \quad \forall i \in I^{N D} \\
& \sum_{j} \lambda_{j} \hat{y}_{k j} \geq \hat{y}_{k} \geq \hat{y}_{k 0} \quad \forall k \in O^{D} \\
& \sum_{j} \lambda_{j} \hat{y}_{k j} \geq \hat{y}_{k}=\hat{y}_{k 0} \quad \forall k \in O^{N D} \\
& \sum_{j} \lambda_{j}=1 \\
& \lambda_{j} \geq 0 \forall j \quad \hat{x}_{i} \text { free } \forall i \quad \hat{y}_{k} \text { free } \forall k
\end{aligned}
$$

Therefore for non-discretionary inputs and outputs, both the ideal and the target values are fixed to the value of DMU 0 . This means that the $l_{p}$ distance involves only the discretionary input and output indices. No more changes are necessary to handle non-discretionary variables.

Similarly, although it will not be explicitly formulated, the proposed CP DEA approach can be similarly extended to handle integer variables and undesirable outputs. To this end the DEA technologies proposed by Lozano and Villa (2006) and Kuosmanen (2005) can be used, respectively.

Finally, a possible criticism of our proposed CP-DEA approach is that, since it gets as closest as possible to the ideal point, it tends to compute efficient targets that may be far from the unit under evaluation. This is the usual case in DEA although it is opposite to the concept of least distant target (e.g. Aparicio 2016, Aparicio et al. 2007, 2017). However, if the obtained efficient target is so ambitious in terms of the suggested input and output improvements that the corresponding changes cannot be accomplished by the DMU in a single step, they can be divided 
into a sequence of smaller, monotonous and bounded changes leading to the final target in the spirit of stepwise benchmarking paths (e.g. Lozano and Villa 2005, 2010, Lozano and CalzadaInfante 2018, Nasrabadi et al 2019, Dehnokhalaji and Soltani 2019). Due to the convexity assumption for the PPS, all intermediate benchmarks along the segment connecting DMU 0 to the target computed by the proposed approach are feasible and, hence, it is easy to compute a sequence of intermediate targets leading to the final computed benchmark.

\section{Illustration}

In this section, the proposed target setting approach is illustrated with a small single-input/singleoutput dataset. Table 3 presents the input and output values for six DMUs labelled as A, B,..., F. and their corresponding ideal points. It can be seen that DMUs A, B, C and D are efficient and their ideal point coincide with themselves. Therefore, we only need to solve model (7) for units E and F. We consider the objective function (8) for $1<p<\infty$, (14) for $p=1$ and (15) for $p=\infty$ and three different scenarios: one unweighted case and two weighted scenarios corresponding to $w=\left(w^{x}, w^{y}\right)=(2 / 3,1 / 3)$ and $w=(1 / 3,2 / 3)$. The illustrative example has also been solved applying MEA approach proposed by Asmild and Pastor (2010), with the corresponding target and efficiency scores reported in Table 3.

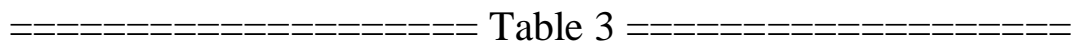

Table 4 reports the results of CP-DEA method for units E and F. Note that the targets for the weighted scenarios enhance the improvement of variables with larger weights (at the expense of others), where improvement means reduction in inputs and increment in outputs. The obtained target generally depends on the value of parameter $p$ although sometimes the targets for two different values of $p$ may be close. This can be seen in Figures 1 and 2 as well, which show the targets corresponding to units $\mathrm{E}$ and $\mathrm{F}$, respectively, for all three scenarios and for all three values for $p$. To avoid clutter, the iso-distance curves are plotted only for $p=2$. Note that although in the unweighted case they are circles in the dimensionless PPS, they become ellipses in the original PPS. For comparison, Figures 1 and 2 also show the corresponding MEA target, which does not assume any preference structure and hence is similar to the unweighted scenario. 


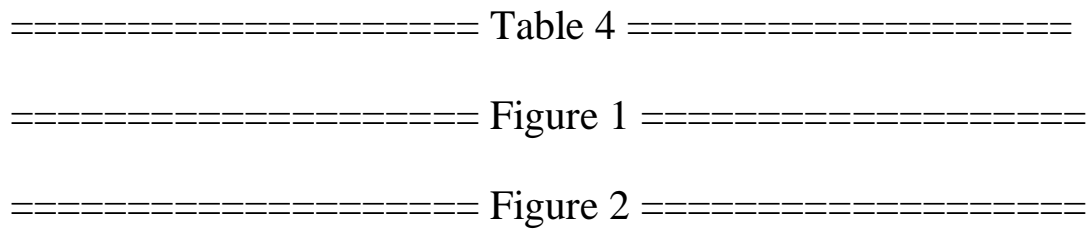

About the efficiency scores $\xi_{0}^{p}$, it is rational that, for a given value of $p$, they differ from the unweighted case to weighted cases since each case involves a different scenario. Thus, even if the computed target is the same as it happens for unit $\mathrm{F}$ in the unweighted and the $w=(2 / 3,1 / 3)$ scenarios, the corresponding efficiency scores differ because the weighted and the unweighted $l_{\mathrm{p}}$ distances are different. Similarly, for a given scenario, it is clear that the efficiency score depends on the value of parameter $p$ as it influences the way the $l_{p}$ distance is computed.

Finally, for the sake of comparison, we have also considered the gradual improvement approach of Dehnokhalaji and Soltani (2019) that computes a sequence of targets for each unit. The lower bounds of admissible changes of inputs and the upper bounds of admissible changes of output at each step have been set to 0.1 (i.e. 10\%) for this problem. The corresponding results are reported in Table 5. As it can be seen, five steps and two steps are required for inefficient units $\mathrm{E}$ and $\mathrm{F}$, respectively, to reach the efficient frontier so that the returns to scale of the target is the same as that of the unit under evaluation. Figure 3 shows those the successive targets for DMUs E and F. Note that the conventional single-step projection approach for those two units involves inputs and outputs changes larger than $10 \%$.

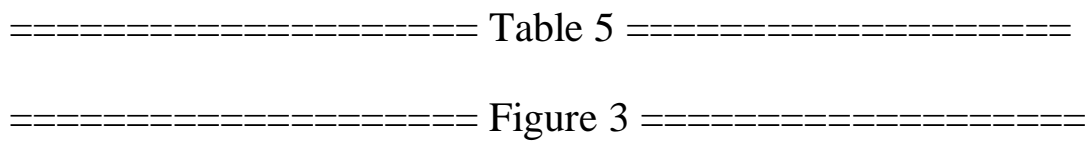

\section{Numerical experiments}

In this section the proposed CP-DEA approach is extensively compared with different DEA approaches on the dataset used in Asmild and Pastor (2010). The dataset includes observations for 27 OECD countries and considers four inputs (practicing physicians per $10^{3}$ population, inpatient beds per 1000 population, Magnetic Resonance Imaging MRI units per $10^{6}$ population, healthcare expenditure expressed as \% of GDP) and two outputs (life expectancy and infant 
survival rate). Of the four inputs, only the one corresponding to the expenditure on healthcare is considered discretionary.

After normalizing the data, the first step of the proposed approach is computing the ideal point for each DMU which are reported in an un-normalized form, in Table 6. The table also shows the standard deviations coefficient used to normalize the corresponding inputs and outputs. For the 14 efficient DMUs, whose rows are shown in bold in Table 6, their ideal point coincides with the observed DMU itself. For the rest of units, the ideal point dominates the observed DMU and is not attainable in general.

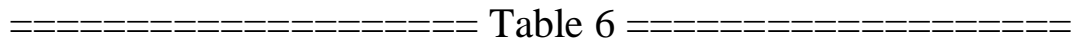

Table 7 shows the targets computed by the proposed CP-DEA approach for the inefficient DMUs using $p=1, p=2$ and $p=\infty$. For $p=1$, from the dual variables of the optimal solution of model (7) it was detected that for all the inefficient DMUs there were no alternative optima and hence it was not necessary to solve the phase II specified in (14). For $p=\infty$ this happened but only for some DMUs (namely Hungary, Portugal and USA). For the rest, the phase II in (15) was solved to select among the alternative optima of the phase I as per (15).

For comparison, the dataset was also solved using different DEA approaches, namely the slacksbased measure of efficiency (SBM) of Tone (2001), the range directional model (RDM) and MEA of Asmild and Pastor (2010), the largest improvement approach of Hampf and Krüger (2015) and the potential-based measure of efficiency (PBM) of Soltani and Lozano (2018). The corresponding targets are shown in Table 8. Note that the targets computed by SBM, PBM and Hampf and Krüger (2015) coincide for all inefficient DMUs. This certainly does not hold in general, as those methods differ significantly in the criterion used to compute the targets.

=ニニニニニニニニニニニニニニニニニ= Table 8 =ニ=ニニニニニニニニ=ニニニニニニ 
The differences between the targets computed by the different methods should be analyzed for each DMU separately. Thus, for example, Figure 4 uses parallel coordinates to show those targets for USA. Note that the target computed by CP-DEA for $p=1$ is similar to those of RDM and MEA. The targets computed by CP-DEA for $p=2$ and $p=\infty$ are somewhat more demanding in the input side and less demanding for the outputs. They are thus closer to the target computed by SBM, Hampf and Krüger (2015) and PBM, which concentrates all improvements only in the input.

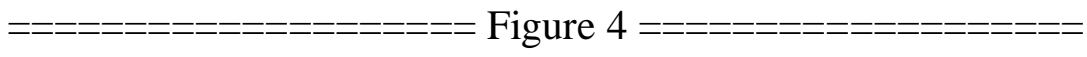

Tables 9,10 and 11 show the $l_{\mathrm{p}}$ distance between the targets computed by the different methods and the ideal point for $p=1, p=2$ and $p=\infty$, respectively. For each row, the minimum $l_{p}$ distance is shown in bold and occurs, as expected, for the proposed CP-DEA approach. This supports the assertion that the CP-DEA targets are ambitious since they are as close as possible to the ideal point.

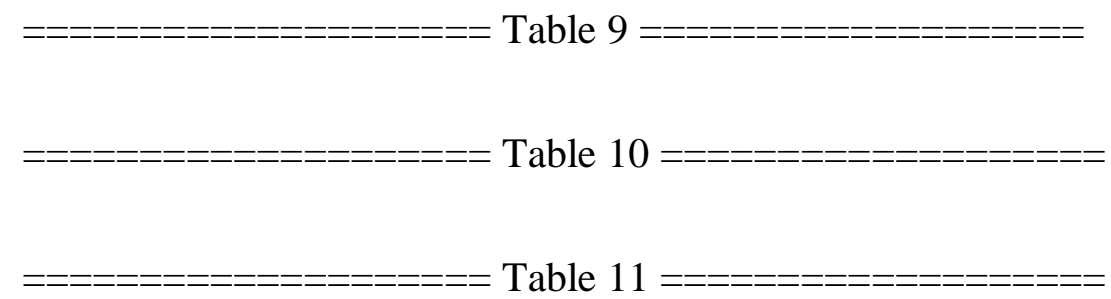

Finally, Tables 12 and 13 provide the efficiency scores (inefficiency score in the case of Hampf and Krüger 2015) computed by the different methods as well as the corresponding Spearman's rank correlation coefficients between them. Note that CP-DEA is the method that provides the largest range in efficiency scores, with scores as low as 0.198. Compare that with the opposite case of PBM, whose lowest efficiency score is 0.879 . This can be interpreted as that the proposed approach emphasizes computing ambitious efficient targets (in the sense of being as close as possible to the ideal operating point) and hence tries to improve the inputs and outputs as much as possible. This is the opposite of computing the closest target and hence can lead to lower efficiency scores. Finally, note that the CP-DEA efficiency scores seem to be highly correlated with those of PBM and Hampf and Krüger (2015) and less so with SBM, RDM and MEA. 


\section{Conclusions}

This paper presents a novel CP-based approach for target setting in DEA. It is based on the belief that DEA target setting should be approached as a multiobjective optimization problem and in the fact that $\mathrm{CP}$ is a multiobjective optimization method that requires no preference information and hence is both simple and effective. It also has a simple graphical interpretation that helps to understand how it works. CP has already been applied in DEA but using CSW formulations with the aim of ranking the DMUs. The proposed CP-DEA approach utilizes an envelopment formulation based on the ideal point associated to each DMU. There are some DEA approaches (e.g. MEA) that use such ideal point to orient a directional vector and solve the corresponding DDF model but CP works differently. Instead of computing the target from within the PPS, CP looks at the PPS from outside, specifically from the ideal point, and then computes the closest feasible point from the PPS applying an $l_{p}$ metric. This method has an interesting geometric interpretation considering the iso-distance curves centered at the ideal point. Thus, the computed target corresponds to the iso-distance curve that is tangent to the PPS.

$\mathrm{CP}$ is a one-parameter family of solutions so that different values of the parameter $p$ can be used. In this paper, the three values of $p$ most commonly used in the literature, namely $p=1, p=2$ and $p=\infty$ were explicitly formulated and discussed. Although the cases $p=1$ and $p=\infty$ result in LP formulations, the optimal solution of the corresponding CP model may not be unique, leading us to apply a lexicographic approach (with a secondary goal). Since the Euclidean distance provides a QP and guarantees a unique solution, it is rational to use the minimization of the Euclidean distance as a secondary goal for $p=1$ and $p=\infty$ cases.

Since the proposed CP-DEA models have been formulated on the dimensionless PPS obtained by normalizing the input and output variables using the standard deviation, the proposed approach is translation and units invariant, if VRS assumption holds, and units invariant in CRS case. An efficiency score, based on the $l_{p}$ distance from the DMU to its computed target, is also defined. 
The proposed CP-DEA approach can also be applied to situations with preference structure, undesirable outputs and non-discretionary or integer variables.

The results of the computational experiments on a dataset from the literature indicate that there are small differences between the targets computed for different values of $p$ and between these and those of other methods. In any case, the CP-DEA targets are, by construction, the ones that are closest to the corresponding ideal points. This translates into ambitious targets. Also, although this does not need to happen in general, the CP-DEA efficiency scores seem to be highly correlated with those of PBM and Hampf and Krüger (2015) and less so with SBM, RDM and MEA methods.

Although the proposed approach is quite effective in computing ambitious, efficient targets it has also some limitations and drawbacks. One is that the target computed depends on the value of parameter $p$ chosen and only in the case of $p=1$ and $p=\infty$ the resulting model is LP. For both values of $\mathrm{p}$ a phase II is generally needed to select among the alternative optima. Also, for some DMUs the computed target may be distant from the ideal point thus leading to a low efficiency score.

As mentioned above, the proposed approach considered a perspective from outside the PPS which makes it different from the traditional DEA target setting models. This perspective is in common with other multi-objective optimization methods (like Weighted Tchebycheff) as well as bargaining problem solutions (like the Equal Loss and Claims Egalitarian solutions), which could also be applied in DEA. Other topics for further research can be extending CP-DEA to centralized, network and fuzzy DEA contexts.

\section{Acknowledgements}

This research was carried out with the financial support of the Spanish Ministry of Economy, Industry and Competitiveness and the European Regional Development Fund, grant DPI201785343-P. Narges Soltani acknowledges the support of a grant from the Ministry of Science, Research and Technology of the Islamic Republic of Iran. 


\section{References}

Aparicio, J., Ruíz, J.L. and Sirvent, I., "Closest targets and minimum distance to the Paretoefficient frontier in DEA”, Journal of Productivity Analysis, 28 (2007) 209-218

Aparicio, J., "A survey on measuring efficiency through the determination of the least distance in data envelopment analysis", Journal of Centrum Cathedra, 9, 2 (2016) 143-167

Aparicio, J., Cordero, J.M. and Pastor, J.T., "The determination of the least distance to the strongly efficient frontier in Data Envelopment Analysis oriented models: Modelling and computational aspects", Omega, 71 (2017) 1-10

Asmild, M. and Pastor, J.T., Slack free MEA and RDM with comprehensive efficiency measures, Omega, 38 (2010) 475-483

Banker, R.D., Charnes, A. and Cooper, W.W., "Some models for estimating technical and scale inefficiencies in data envelopment analysis”, Management Science, 30, 9 (1984) 1078-1092

Banker, R.D. and Morey, R., "Efficiency analysis for exogenously fixed inputs and outputs", Operations Research, 34 (1986) 513-521

Carrillo, M. and Jorge, J.M., “A multiobjective DEA approach to ranking alternatives”, Expert Systems with Applications, 50 (2016) 130-139

Chen, Y.W., Larbani, M. and Chang, Y.P., "Multiobjective data envelopment analysis", Journal of the Operational Research Society, 60 (2009) 1556-1566

Cook, W.D. and Zhu, J., "Within-group common weights in DEA: An analysis of power plant efficiency”, European Journal of Operational Research, 178 (2007) 207-216

Cooper, W.W., Park, K.S. and Pastor, J.T., "RAM: A Range Adjusted Measure of Inefficiency for Use with Additive Models, and Relations to Other Models and Measures in DEA", Journal of Productivity Analysis, 11, 1 (1999) 5-42

Cooper, W.W., Seiford, L.M. and Zhu, J., Handbook on Data Envelopment Analysis, Springer, New York, 2004

Cooper, W.W., Seiford, L.M. and Tone, K., Data Envelopment Analysis: A Comprehensive Text with Models, Applications, References and DEA-Solver Software, 2nd edition, Springer, New York, 2006 
Davoodi, A. and Rezai, H.Z., "Common set of weights in data envelopment analysis: a linear programming problem", Central European Journal of Operational Research, 20 (2012) 355-365

Dehnokhalaji, A. and Soltani, N., "Gradual efficiency improvement through a sequence of targets", Journal of the Operational Research Society, 70, 12 (2019) 2143-2152

Despotis, D.K., "Improving the discriminating power of DEA: focus on globally efficient units", Journal of the Operational Research Society, 53 (2002) 314-323

Despotis, D.K., Sotiros, D. and Koronakos, G., "A network DEA approach for series multi-stage processes", Omega, 61 (2016) 35-48

Ebrahimnejad, A. and Tavana, M., "An interactive MOLP method for identifying target units in output-oriented DEA models: The NATO enlargement problem", Measurement, 52 (2014) 124134

Färe, R., Grosskopf, S. and Wittaker, G., "Directional output distance functions: Endogenous constraints based on exogenous normalization constraints", Journal of Productivity Analysis, 40 (2013) 267-269

Freimer, M. and Yu, P.L., "Some new results on compromise solutions for group decision problems", Management Science, 22, 6 (1976) 688-693

Fukuyama, H. and Weber, W.L., "A directional slacks-based measure of technical inefficiency, Socio-Economic Planning Sciences, 43, 4 (2009) 274-287

Gutiérrez, E. and Lozano, S., "Efficiency assessment and output maximization possibilities of European small and medium sized airports", Research in Transportation Economics, 56 (2016) $3-14$

Hampf, B. and Krüger, J. J., "Optimal directions for directional distance functions: An exploration of potential reductions of greenhouse gases", American Journal of Agricultural Economics, 97, 3 (2015) 920-938

Hashimoto, A. and Wu, D.A., "A DEA- Compromise Programming model for comprehensive ranking", Journal of the Operations Research Society of Japan, 47, 2 (2004) 73-81 
Hosseinzadeh Lotfi, F., Jahanshaloo, G.R. and Memariani, A., "A Method for Finding Common Set of Weights by Multiple Objective programming in Data Envelopment Analysis", Southwest Journal of Pure and Applied Mathematics, 1 (2000) 44-54

Kao, C., "Weight determination for consistently ranking alternatives in multiple criteria decision analysis", Applied Mathematical Modelling, 34 (2010) 1779-1787

Kao, C. and Hung, H.T., "Data envelopment analysis with common weights: the compromise solution approach", Journal of the Operational Research Society, 56 (2005) 1196-1203

Korhonen, P.J., Dehnokhalaji, A. and Nasrabadi, N., "A lexicographic radial projection onto the efficient frontier in Data Envelopment Analysis", European Journal of Operational Research, 265 (2018) 1005-1012

Kuosmanen, T., "Weak disposability in nonparametric production analysis with undesirable outputs", American Journal of Agricultural Economics, 87, 4 (2005) 1077-1082

Lee, C.Y., "Mixed-strategy Nash equilibrium in data envelopment analysis", European Journal of Operational Research, 266 (2018) 1013-1024

Lozano, S. and Villa, G., "Determining a sequence of targets in DEA", Journal of the Operational Research Society, 56 (2005) 1439-1447

Lozano, S. and Villa, G., "Data envelopment analysis of integer-valued inputs and outputs", Computer and Operations Research, 33, 10 (2006) 3004-3014

Lozano, S. and Villa, G., "Gradual technical and scale efficiency improvement in DEA", Annals of Operations Research, 173 (2010) 123-136

Lozano, S. and Calzada-Infante, L., "Computing gradient-based stepwise benchmarking paths", Omega, 81 (2018) 195-207

Marler, R.T., and Arora, J.S., "Survey of Multi-Objective Optimization Methods for Engineering", Structural and Multidisciplinary Optimization, 26, 6 (2004) 369-395

Nasrabadi, N., Dehnokhalaji, A., Korhonen, P. and Wallenius, J., "A stepwise benchmarking approach to DEA with interval scale data", Journal of the Operational Research Society, 70, 6 (2019) 954-961 
Pastor, J.T., Aparicio, J., Alcaraz, J., Vidal, F. and Pastor, D., "The Reverse Directional Distance Function", in Advances in Efficiency and Productivity, J. Aparicio et al. (eds.), International Series in Operations Research \& Management Science, 249 (2016) 15-55

Roll, Y. and Golany, B., "Alternate Methods Weights of Treating Factor in DEA”, Omega, 21, 1 (1993) 99-109

Soltani, N. and Lozano, S., "Potential-Based Efficiency Assessment and Target Setting", Computers and Industrial Engineering, 126 (2018) 611-624

Sun, J., Wu, J. and Guo, D., "Performance ranking of units considering ideal and anti-ideal DMU with common weights", Applied Mathematical Modelling, 37 (2013) 6301-6310

Tavana, M., Ebrahimnejad, A., Santos-Arteaga, F.J., Mansourzadeh, S.M. and Matin, R.K., “A hybrid DEA-MOLP model for public school assessment and closure decision in the City of Philadelphia", Socio-Economic Planning Sciences, 61 (2018) 70-89

Thomson, W., "Cooperative models of bargaining", in Handbook of Game Theory, Volume 2, Aumann, R.J. and Hart, S. (Eds.), North-Holland (1994) 1237-1284

Tone, K., "A slacks-based measure of efficiency in data envelopment analysis", European Journal of Operational Research, 130, 3 (2001) 498-509

Wang, K., Xian, Y., Lee, C.Y., Wei, Y.M. and Huang, Z., "On selecting directions for directional distance functions in a non-parametric framework: a review", Annals of Operations Research, 278 (2019) 43-76

Wang, Y.M. and Luo, Y., "DEA efficiency assessment using ideal and anti-ideal decision making units", Applied Mathematics and Computation, 173 (2006) 902-915

Wang, Y.M., Luo, Y. and Lan, Y.X., "Common weights for fully ranking decision making units by regression analysis", Expert Systems with Applications, 38 (2011a) 9122-9128

Wang, Y.M., Chin, K.S. and Luo, Y., "Cross-efficiency evaluation based on ideal and anti-ideal decision making units", Expert Systems with Applications, 38 (2011b) 10312-10319

Yu, P.L., "A class of solutions for group decision problems", Management Science, 19, 8 (1973) 936-946 
Zohrehbandian, M., Makui, A. and Alinezhad, A., "A compromise solution approach for finding common weights in DEA: an improvement to Kao and Hung's approach", Journal of the Operational Research Society, 61 (2010) 604-610 


\section{List of figure and table captions}

Table 1. Classification of DEA CP CSW approaches

Table 2. DEA CP CSW models formulations

Table 3. Illustration of the dataset, ideal points and MEA results

Table 4. CP-DEA targets and efficiency scores for units $\mathrm{E}$ and $\mathrm{F}$

Table 5. Sequence of targets and efficiency scores for units E and F computed by Dehnokhalaji and Soltani (2019)

Table 6. Ideal points and normalizing coefficients (efficient DMUs in bold)

Table 7. CP-DEA targets for inefficient DMUs for $p=1, p=2$ and $p=\infty$

Table 8. Targets for inefficient DMUs computed by different DEA approaches

Table $9 . l_{1}$ distance from the different targets to the ideal point

Table 10. $l_{2}$ distance from the different targets to the ideal point

Table 11. $l_{\infty}$ distance from the different targets to the ideal point

Table 12. Efficiency scores computed by different DEA approaches

Table 13. Spearman's rank correlation coefficients between the different DEA approaches

Figure 1. Visualization of the CP-DEA targets for unit E

Figure 2. Visualization of the CP-DEA targets for unit F

Figure 3. Visualization of the sequence of targets computed by Dehnokhalaji and Soltani (2019) for units $\mathrm{E}$ and $\mathrm{F}$

Figure 4. Parallel coordinates representation of the computed targets for USA 


\begin{tabular}{|c|c|c|c|c|}
\hline $\begin{array}{l}\text { Efficiency } \\
\text { measure }\end{array}$ & $\begin{array}{l}\text { Ideal } \\
\text { point }\end{array}$ & $p=1$ & $\mathbf{p}=\infty$ & Other \\
\hline \multirow{3}{*}{ ratio } & $\overline{\mathbf{1}}$ & $\begin{array}{c}\text { Roll and Golani (1993) } \\
\text { Hosseinzadeh Lofti et al. (2000) } \\
\text { Davoodi and Rezai (2012) }\end{array}$ & - & Hatami-Marbini et al. (2015) \\
\hline & $\begin{array}{c}\overline{\mathbf{0}} \\
(\text { anti- } \\
\text { ideal) }\end{array}$ & - & Jahanshaloo et al. (2005) & - \\
\hline & $\boldsymbol{\theta}^{C C R}$ & $\begin{array}{l}\text { Despotis (2002) } \\
\text { Kao and Hung (2005) } \\
\text { Cook and Zhu (2007) }\end{array}$ & $\begin{array}{c}\text { Despotis (2002) } \\
\text { Kao and Hung (2005) }\end{array}$ & $\begin{array}{l}\text { Despotis (2002) } \\
\text { Kao and Hung (2005) } \\
\text { Wang et al. (2011a) }\end{array}$ \\
\hline \multirow{2}{*}{ difference } & $\overline{\mathbf{1}}$ & $\begin{array}{l}\text { Chiang et al. (2011) } \\
\text { Hosseinzadeh Lofti et al. (2013) }\end{array}$ & Chen et al. (2009) & - \\
\hline & $\boldsymbol{\theta}^{C C R}$ & $\begin{array}{l}\text { Zohrehbandian et al. (2010) } \\
\text { Omrani (2014) }\end{array}$ & Zohrehbandian et al. (2010) & $\begin{array}{c}\text { Despotis (2002) } \\
\text { Wang et al. (2011a) }\end{array}$ \\
\hline
\end{tabular}

Table 1. Classification of DEA CP CSW approaches 


\begin{tabular}{|c|c|c|}
\hline Reference & Model & Remarks \\
\hline Roll and Golani (1993) & $\begin{array}{l}\operatorname{Max} \sum_{j} E_{j} \\
\text { s.t. } \\
E_{j} \leq 1 \quad \forall j\end{array}$ & $\begin{array}{l}\text { Non-linear } \\
\text { Equivalent to } p=1 \text { model in } \\
\text { Kao and Hung }(2005)\end{array}$ \\
\hline $\begin{array}{l}\text { Hosseinzadeh Lofti et al. } \\
(2000)\end{array}$ & $\begin{array}{l}\operatorname{Min} \sum_{j} d_{j} \\
\text { s.t. } \\
E_{j}+d_{j}=1 \quad \forall j \\
d_{j} \geq 0 \quad \forall j\end{array}$ & $\begin{array}{l}\text { Non-linear } \\
\text { Equivalent to Roll and } \\
\text { Golani (1993) and } p=1 \\
\text { model in Kao and Hung } \\
(2005)\end{array}$ \\
\hline Davoodi and Rezai (2012) & $\begin{array}{l}\operatorname{Min} \sum_{j} d_{j} \\
\text { s.t. } \\
E_{j}=\frac{\sum_{k} v_{k} y_{k j}+\xi}{\sum_{i} u_{i} x_{i j}} \forall j \\
E_{j}+d_{j}=1 \quad \forall j \\
d_{j} \geq 0 \quad \forall j \quad \xi \text { free }\end{array}$ & $\begin{array}{l}\text { VRS } \\
\text { Can be linearized }\end{array}$ \\
\hline Hatami-Marbini et al. (2015) & $\begin{array}{l}\operatorname{Min} \sum_{j} s_{j} \\
\text { s.t. } \\
E_{j}=\frac{\sum_{k} v_{k} y_{k j}+s_{j}}{\sum_{i} u_{i} x_{i j}}=1 \quad \forall j \\
s_{j} \geq 0 \quad \forall j\end{array}$ & $\begin{array}{l}s_{j} \text { virtual gap } \\
\text { LP }\end{array}$ \\
\hline Jahanshaloo et al. (2005) & $\begin{array}{l}\underset{j}{\operatorname{Max}} \underset{\text { s.t. }}{\operatorname{Min} E_{j}} \\
E_{j}=\frac{\sum_{k} v_{k} y_{k j}+\xi}{\sum_{i} u_{i} x_{i j}} \forall j \\
E_{j} \leq 1 \quad \forall j \\
\xi \text { free }\end{array}$ & $\begin{array}{l}\text { VRS } \\
\text { Non-linear }\end{array}$ \\
\hline Wang et al. (2011a) & $\operatorname{Min} \sum_{j}\left(\theta_{j}^{C C R}-E_{j}\right)^{2}$ & $\begin{array}{l}\text { Least Squares error } \\
\text { regression } \\
\text { Non-linear }\end{array}$ \\
\hline
\end{tabular}

Table 2. DEA CP CSW models formulations 


\begin{tabular}{|c|c|c|}
\hline Reference & Model & Remarks \\
\hline Despotis (2002) & $\begin{array}{l}\operatorname{Min} \quad \alpha \cdot \sum_{j} d_{j}+(1-\alpha) \cdot d_{\max } \\
\text { s.t. } \\
E_{j}+d_{j}=\theta_{j}^{C C R} \quad \forall j \\
d_{\max } \geq d_{j} \quad \forall j \\
d_{j} \geq 0 \quad \forall j\end{array}$ & $\begin{array}{l}\text { Non-linear } \\
0 \leq \alpha \leq 1\end{array}$ \\
\hline \multirow{3}{*}{ Kao and Hung (2005) } & $\begin{array}{l}\operatorname{Min} \sum_{j}\left(\theta_{j}^{C C R}-E_{j}\right) \\
\text { s.t. } \\
E_{j} \leq 1 \quad \forall j\end{array}$ & $\begin{array}{l}p=1 \\
\text { Non-linear }\end{array}$ \\
\hline & $\begin{array}{l}\operatorname{Min} \sum_{j}\left(\theta_{j}^{C C R}-E_{j}\right)^{2} \\
\text { s.t. } \\
E_{j} \leq 1 \quad \forall j\end{array}$ & $\begin{array}{l}p=2 \\
\text { Non-linear }\end{array}$ \\
\hline & $\begin{array}{l}\operatorname{Min} \operatorname{Max}_{j}\left(\theta_{j}^{C C R}-E_{j}\right) \\
\text { s.t. } \\
E_{j} \leq 1 \quad \forall j\end{array}$ & $\begin{array}{l}p=\infty \\
\text { Non-linear }\end{array}$ \\
\hline Cook and Zhu (2007) & $\begin{array}{l}\text { Min } \quad \sum_{j \in J} d_{j} \\
\text { s.t. } \\
E_{j} \leq 1 \quad \forall j \\
E_{j}+d_{j}=\theta_{j}^{C C R} \quad \forall j \in J \\
d_{j} \geq 0 \forall j \in J\end{array}$ & $\begin{array}{l}\text { Within-group } \mathrm{J} \text { common } \\
\text { weights } \\
J \subset\{1,2, \ldots, n\} \\
\text { Non-linear }\end{array}$ \\
\hline $\begin{array}{l}\text { Chiang et al. (2011) } \\
\text { Hosseinzadeh Lofti et al. (2013) }\end{array}$ & $\begin{array}{l}\operatorname{Min} \sum_{j} \hat{\hat{d}}_{j} \\
\text { s.t. } \\
\sum_{k} v_{k} y_{k j}-\sum_{i} u_{i} x_{i j}+\hat{\hat{d}}_{j}=0 \quad \forall j \\
\hat{\hat{d}}_{j} \geq 0 \forall j\end{array}$ & LP \\
\hline
\end{tabular}

Table 2. DEA CP CSW models formulations (cont.) 


\begin{tabular}{|c|c|c|}
\hline Reference & Model & Remarks \\
\hline Chen et al. (2009) & 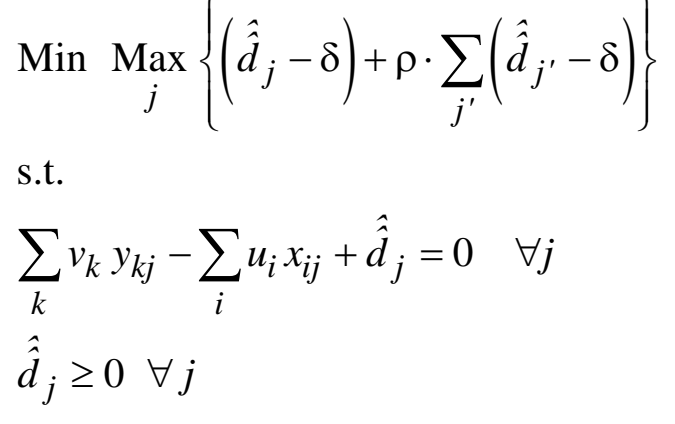 & $\begin{array}{l}\delta, \rho \text { small positive } \\
\text { numbers } \\
\text { LP }\end{array}$ \\
\hline $\begin{array}{l}\text { Zohrehbandian et al. } \\
\text { (2010) } \\
\text { Omrani (2014) }\end{array}$ & $\begin{array}{l}\text { Min } \sum_{j} \hat{d}_{j} \\
\text { s.t. } \\
\sum_{k} v_{k} y_{k j}-\theta_{j}^{C C R} \cdot \sum_{i} u_{i} x_{i j}+\hat{d}_{j}=0 \quad \forall j \\
\sum_{i} u_{i}+\sum_{k} v_{k}=1 \\
\hat{d}_{j} \geq 0 \forall j\end{array}$ & LP \\
\hline Despotis (2002) & $\begin{array}{l}\operatorname{Min} \quad \alpha \cdot \sum_{j} \hat{d}_{j}+(1-\alpha) \cdot \hat{d}_{\max } \\
\text { s.t. } \\
\sum_{k} v_{k} y_{k j}-\theta_{j}^{C C R} \cdot \sum_{i} u_{i} x_{i j}+\hat{d}_{j}=0 \quad \forall j \\
\hat{d}_{\max } \geq \hat{d}_{j} \quad \forall j \\
\hat{d}_{j} \geq 0 \quad \forall j\end{array}$ & $\begin{array}{l}\text { Surrogate formulation } \\
0<\alpha \leq 1 \\
\text { LP }\end{array}$ \\
\hline Wang et al. (2011) & $\begin{array}{l}\operatorname{Min} \sum_{j}\left(\hat{d}_{j}\right)^{2} \\
\text { s.t. } \\
\sum_{k} v_{k} y_{k j}-\theta_{j}^{C C R} \cdot \sum_{i} u_{i} x_{i j}+\hat{d}_{j}=0 \quad \forall j \\
\sum_{i} u_{i} \sum_{j} x_{i j}+\sum_{k} v_{k} \sum_{j} y_{k j}=n \\
\hat{d}_{j} \text { free } \forall j\end{array}$ & $\begin{array}{l}\text { Least Squares error } \\
\text { regression } \\
\text { Non-linear }\end{array}$ \\
\hline
\end{tabular}

Table 2. DEA CP CSW models formulations (cont.) 


\begin{tabular}{|c|c|c|c|c|c|c|c|}
\hline \multirow[b]{2}{*}{ DMU } & \multirow[b]{2}{*}{$x$} & \multirow[b]{2}{*}{$y$} & \multicolumn{2}{|c|}{ Ideal point } & \multicolumn{3}{|c|}{ MEA } \\
\hline & & & $x^{\min }$ & $y^{\max }$ & $x^{M E A}$ & $y^{M E A}$ & $\begin{array}{c}\text { Efficiency Score } \\
\Gamma^{M E A}\end{array}$ \\
\hline A & 2 & 1 & 2 & 1 & 2 & 1 & 1.000 \\
\hline B & 3 & 4 & 3 & 4 & 3 & 4 & 1.000 \\
\hline $\mathrm{C}$ & 4 & 5 & 4 & 5 & 4 & 5 & 1.000 \\
\hline D & 6 & 6 & 6 & 6 & 6 & 6 & 1.000 \\
\hline $\mathrm{E}$ & 5 & 3 & 2.67 & 5.50 & 3.55 & 4.55 & 0.500 \\
\hline $\mathrm{F}$ & 7 & 5.2 & 4.40 & 6 & 5.39 & 5.70 & 0.530 \\
\hline $\begin{array}{l}\text { Standard } \\
\text { deviation }\end{array}$ & 1.87 & 1.81 & & & & & \\
\hline
\end{tabular}

Table 3. Illustration of the dataset, ideal points and MEA results 


\begin{tabular}{|c|c|c|c|c|c|c|c|c|c|}
\hline DMU E & \multicolumn{3}{|c|}{$p=1$} & \multicolumn{3}{|c|}{$p=2$} & \multicolumn{3}{|c|}{$p=\infty$} \\
\hline Scenario & $\hat{x}^{*}$ & $\hat{y}^{*}$ & $\xi_{0}^{p}$ & $\hat{x}^{*}$ & $\hat{y}^{*}$ & $\xi_{0}^{p}$ & $\hat{x}^{*}$ & $\hat{y}^{*}$ & $\xi_{0}^{p}$ \\
\hline Unweighted & 4 & 5 & 0.379 & 3.61 & 4.61 & 0.463 & 3.60 & 4.60 & 0.531 \\
\hline$w=(2 / 3,1 / 3)$ & 3 & 4 & 0.527 & 3.05 & 4.05 & 0.581 & 3.29 & 4.29 & 0.621 \\
\hline$w=(1 / 3,2 / 3)$ & 5 & 5.50 & 0.521 & 4 & 5 & 0.569 & 3.90 & 4.90 & 0.588 \\
\hline DMU F & \multicolumn{3}{|c|}{$p=1$} & \multicolumn{3}{|c|}{$p=2$} & \multicolumn{3}{|c|}{$p=\infty$} \\
\hline Scenario & $\hat{x}^{*}$ & $\hat{y}^{*}$ & $\xi_{0}^{p}$ & $\hat{x}^{*}$ & $\hat{y}^{*}$ & $\xi_{0}^{p}$ & $\hat{x}^{*}$ & $\hat{y}^{*}$ & $\xi_{0}^{p}$ \\
\hline Unweighted & 4.40 & 5.20 & 0.418 & 4.74 & 5.37 & 0.452 & 4.94 & 5.47 & 0.476 \\
\hline$w=(2 / 3,1 / 3)$ & 4.40 & 5.20 & 0.519 & 4.50 & 5.25 & 0.529 & 4.73 & 5.36 & 0.553 \\
\hline$w=(1 / 3,2 / 3)$ & 6 & 6 & 0.679 & 5.23 & 5.61 & 0.740 & 5.21 & 5.61 & 0.758 \\
\hline
\end{tabular}

Table 4. CP-DEA targets and efficiency scores for units E and F 


\begin{tabular}{|c|c|c|c|c|c|c|c|c|}
\hline DMU & & Step 0 & Step 1 & Step 2 & Step 3 & Step 4 & Step 5 & \\
\hline \multirow{4}{*}{ A } & $\mathrm{x}$ & 2.00 & & & & & & \\
\hline & $\mathrm{y}$ & 1.00 & & & & & & \\
\hline & BCC Eff. Score & 1.00 & & & & & & \\
\hline & $u_{0}^{*}$ & 1.00 & $(\mathrm{NDRS})^{1}$ & & & & & \\
\hline \multirow{4}{*}{ B } & $\mathrm{x}$ & 3.00 & & & & & & \\
\hline & $\mathrm{y}$ & 4.00 & & & & & & \\
\hline & BCC Eff. Score & 1.00 & & & & & & \\
\hline & $u_{0}^{*}$ & 0.56 & $(\mathrm{NDRS})^{1}$ & & & & & \\
\hline \multirow{4}{*}{$\mathrm{C}$} & $\mathrm{x}$ & 4.00 & & & & & & \\
\hline & $\mathrm{y}$ & 5.00 & & & & & & \\
\hline & BCC Eff. Score & 1.00 & & & & & & \\
\hline & $u_{0}^{*}$ & -0.25 & $(\mathrm{NIRS})^{2}$ & & & & & \\
\hline \multirow{4}{*}{$\mathrm{D}$} & $\mathrm{x}$ & 6.00 & & & & & & \\
\hline & $\mathrm{y}$ & 6.00 & & & & & & \\
\hline & BCC Eff. Score & 1.00 & & & & & & \\
\hline & $u_{0}^{*}$ & -1.00 & $(\mathrm{NIRS})^{2}$ & & & & & \\
\hline \multirow{4}{*}{$\mathrm{E}$} & $\mathrm{x}$ & 5.00 & 4.50 & 4.05 & 3.65 & 3.28 & 3.00 & \\
\hline & $\mathrm{y}$ & 3.00 & 3.30 & 3.63 & 3.99 & 4.00 & 4.00 & \\
\hline & BCC Eff. Score & 0.53 & 0.61 & 0.71 & 0.82 & 0.91 & 1.00 & \\
\hline & $u_{0}^{*}$ & 0.33 & 0.37 & 0.41 & 0.46 & 0.51 & 0.56 & $(\mathrm{NDRS})^{1}$ \\
\hline \multirow{4}{*}{$\mathrm{F}$} & $\mathrm{x}$ & 7.00 & 6.30 & 6.00 & & & & \\
\hline & $\mathrm{y}$ & 5.20 & 5.72 & 6.00 & & & & \\
\hline & BCC Eff. Score & 0.63 & 0.86 & 1.00 & & & & \\
\hline & $u_{0}^{*}$ & -0.86 & -0.95 & -1.00 & $(\mathrm{NIRS})^{2}$ & & & \\
\hline
\end{tabular}

Table 5. Sequence of targets and efficiency scores for units E and F computed by Dehnokhalaji and Soltani (2019) 
Inputs

\begin{tabular}{|c|c|c|c|c|c|c|}
\hline DMU & Beds & MRI & Physicians & Expenditure & Infant Survival & Life Expectancy \\
\hline Australia & 8.5 & 4.5 & 2.5 & 8.30 & 0.99581 & 78.813 \\
\hline Austria & 8.9 & 8.4 & 3.0 & 6.82 & 0.99647 & 79.532 \\
\hline Belgium & 7.2 & 3.2 & 3.4 & 7.34 & 0.99580 & 78.803 \\
\hline Canada & 4.7 & 1.8 & 2.1 & 9.49 & 0.99443 & 78.670 \\
\hline Czech republic & 8.9 & 1.4 & 3.0 & 7.15 & 0.99480 & 74.600 \\
\hline Denmark & 4.5 & 2.5 & 3.3 & 8.30 & 0.99523 & 76.200 \\
\hline Finland & 7.8 & 8.7 & 3.0 & 6.91 & 0.99580 & 77.300 \\
\hline France & 8.5 & 2.5 & 3.0 & 8.28 & 0.99563 & 78.745 \\
\hline Germany & 9.3 & 6.2 & 3.5 & 6.94 & 0.99645 & 79.315 \\
\hline Greece & 5.0 & 1.2 & 4.1 & 8.28 & 0.99330 & 77.900 \\
\hline Hungary & 8.3 & 1.5 & 3.1 & 5.35 & 0.99446 & 77.020 \\
\hline Ireland & 3.7 & 0.3 & 2.2 & 6.36 & 0.99380 & 75.960 \\
\hline Italy & 5.9 & 6.4 & 5.9 & 7.22 & 0.99644 & 79.306 \\
\hline Japan & 16.5 & 18.8 & 1.9 & 7.63 & 0.99640 & 80.600 \\
\hline Korea & 5.1 & 4.0 & 1.3 & 5.04 & 0.99224 & 74.470 \\
\hline Mexico & 1.1 & 0.1 & 1.6 & 4.54 & 0.98420 & 74.700 \\
\hline Netherlands & 11.3 & 3.9 & 2.6 & 7.37 & 0.99613 & 78.823 \\
\hline New Zealand & 6.2 & 2.6 & 2.2 & 7.69 & 0.99490 & 78.047 \\
\hline Norway & 14.5 & 0.7 & 2.4 & 8.92 & 0.99600 & 78.400 \\
\hline Poland & 5.3 & 0.4 & 2.4 & 5.67 & 0.99391 & 76.256 \\
\hline Portugal & 4 & 2.8 & 3.1 & 6.44 & 0.99502 & 78.017 \\
\hline Spain & 3.9 & 3.8 & 4.4 & 7.06 & 0.99493 & 78.100 \\
\hline Sweden & 3.8 & 6.8 & 3.1 & 8.37 & 0.99650 & 79.400 \\
\hline Switzerland & 18.1 & 13.2 & 1.9 & 7.46 & 0.99582 & 79.681 \\
\hline Turkey & 2.5 & 0.6 & 1.2 & 3.93 & 0.96210 & 68.700 \\
\hline UK & 4.2 & 3.4 & 1.7 & 6.74 & 0.99430 & 77.270 \\
\hline USA & 3.7 & 7.6 & 2.7 & 6.30 & 0.99519 & 78.685 \\
\hline $\begin{array}{l}\text { Normalization } \\
\text { coefficients }\end{array}$ & 4.129 & 4.264 & 1.005 & 1.959 & 0.007 & 2.683 \\
\hline
\end{tabular}

Table 5. Ideal points and normalizing coefficients (efficient DMUs in bold)

Outputs 


\begin{tabular}{|l|c|c|c|c|c|c|c|c|c|}
\cline { 2 - 9 } \multicolumn{1}{c|}{} & \multicolumn{4}{c|}{$p=1$} & \multicolumn{2}{c|}{$p=2$} & \multicolumn{3}{c|}{$p=\infty$} \\
\cline { 2 - 10 } \multicolumn{1}{c|}{} & Input & \multicolumn{2}{c|}{ Outputs } & Input & \multicolumn{2}{c|}{ Outputs } & Input & \multicolumn{2}{c|}{ Outputs } \\
\hline \multirow{2}{*}{ DMU } & Expenditure & $\begin{array}{c}\text { Infant } \\
\text { Survival }\end{array}$ & $\begin{array}{c}\text { Life } \\
\text { Expectancy }\end{array}$ & Expenditure & $\begin{array}{c}\text { Infant } \\
\text { Survival }\end{array}$ & $\begin{array}{c}\text { Life } \\
\text { Expectancy }\end{array}$ & Expenditure & $\begin{array}{c}\text { Infant } \\
\text { Survival }\end{array}$ & $\begin{array}{c}\text { Life } \\
\text { Expectancy }\end{array}$ \\
\hline Australia & 8.299 & 0.99581 & 78.700 & 8.327 & 0.99580 & 78.715 & 8.359 & 0.99570 & 78.732 \\
Austria & 7.163 & 0.99524 & 78.686 & 7.251 & 0.99534 & 78.755 & 7.340 & 0.99544 & 78.825 \\
Belgium & 7.337 & 0.99501 & 78.000 & 7.607 & 0.99526 & 78.191 & 7.723 & 0.99537 & 78.274 \\
France & 8.284 & 0.99546 & 78.400 & 8.381 & 0.99548 & 78.460 & 8.458 & 0.99550 & 78.507 \\
Germany & 7.308 & 0.99530 & 78.538 & 7.351 & 0.99535 & 78.572 & 7.433 & 0.99544 & 78.638 \\
Hungary & 6.600 & 0.99419 & 76.694 & 6.242 & 0.99295 & 76.263 & 6.035 & 0.99201 & 76.081 \\
Italy & 7.227 & 0.99526 & 78.577 & 7.493 & 0.99554 & 78.754 & 7.581 & 0.99563 & 78.812 \\
Netherlands & 7.372 & 0.99506 & 78.000 & 7.664 & 0.99534 & 78.206 & 7.768 & 0.99544 & 78.281 \\
New Zealand & 7.693 & 0.99469 & 77.800 & 7.760 & 0.99470 & 77.846 & 7.809 & 0.99468 & 77.879 \\
Poland & 6.394 & 0.99385 & 76.064 & 6.180 & 0.99305 & 75.824 & 6.063 & 0.99251 & 75.723 \\
Portugal & 6.802 & 0.99448 & 77.354 & 6.802 & 0.99448 & 77.354 & 6.876 & 0.99400 & 77.420 \\
Switzerland & 7.460 & 0.99578 & 79.500 & 7.509 & 0.99581 & 79.530 & 7.553 & 0.99580 & 79.553 \\
USA & 7.762 & 0.99519 & 78.626 & 7.028 & 0.99397 & 77.774 & 6.961 & 0.99285 & 77.786 \\
\hline
\end{tabular}

Table 6. CP-DEA targets for inefficient DMUs for $\mathrm{p}=1, \mathrm{p}=2$ and $\mathrm{p}=\infty$ 


\begin{tabular}{|c|c|c|c|c|c|c|c|c|c|}
\hline \multirow[b]{3}{*}{ DMU } & \multicolumn{3}{|c|}{ SBM, Hampf and Krüger (2015), PBM } & \multicolumn{3}{|c|}{ RDM } & \multicolumn{3}{|c|}{ MEA } \\
\hline & \multirow{2}{*}{$\frac{\text { Input }}{\text { Expenditure }}$} & \multicolumn{2}{|c|}{ Outputs } & \multirow{2}{*}{$\begin{array}{c}\text { Input } \\
\text { Expenditure }\end{array}$} & \multicolumn{2}{|c|}{ Outputs } & \multirow{2}{*}{$\frac{\text { Input }}{\text { Expenditure }}$} & \multicolumn{2}{|c|}{ Outputs } \\
\hline & & $\begin{array}{c}\text { Infant } \\
\text { Survival }\end{array}$ & $\begin{array}{c}\text { Life } \\
\text { Expectancy }\end{array}$ & & $\begin{array}{c}\text { Infant } \\
\text { Survival }\end{array}$ & $\begin{array}{c}\text { Life } \\
\text { Expectancy }\end{array}$ & & $\begin{array}{c}\text { Infant } \\
\text { Survival }\end{array}$ & $\begin{array}{c}\text { Life } \\
\text { Expectancy }\end{array}$ \\
\hline Australia & 8.299 & 0.99581 & 78.700 & 8.391 & 0.99579 & 78.749 & 8.405 & 0.99579 & 78.757 \\
\hline Austria & 6.824 & 0.99510 & 77.800 & 7.199 & 0.99544 & 78.477 & 7.509 & 0.99581 & 78.694 \\
\hline Belgium & 7.337 & 0.99501 & 78.000 & 7.989 & 0.99551 & 78.447 & 7.993 & 0.99551 & 78.450 \\
\hline France & 8.284 & 0.99546 & 78.400 & 8.857 & 0.99554 & 78.675 & 8.734 & 0.99553 & 78.623 \\
\hline Germany & 6.939 & 0.99530 & 77.600 & 7.750 & 0.99581 & 78.873 & 7.983 & 0.99612 & 78.821 \\
\hline Hungary & 5.349 & 0.99030 & 75.062 & 5.779 & 0.99251 & 75.368 & 5.869 & 0.99297 & 75.432 \\
\hline Italy & 7.220 & 0.99525 & 78.570 & 7.687 & 0.99575 & 78.883 & 7.782 & 0.99585 & 78.946 \\
\hline Netherlands & 7.372 & 0.99506 & 78.000 & 7.906 & 0.99556 & 78.378 & 7.965 & 0.99562 & 78.419 \\
\hline New Zealand & 7.686 & 0.99455 & 77.800 & 7.889 & 0.99472 & 77.929 & 7.881 & 0.99472 & 77.925 \\
\hline Poland & 5.671 & 0.99050 & 75.445 & 5.916 & 0.99176 & 75.619 & 6.027 & 0.99233 & 75.698 \\
\hline Portugal & 6.440 & 0.99400 & 76.519 & 6.881 & 0.99461 & 77.189 & 6.921 & 0.99467 & 77.250 \\
\hline Switzerland & 7.460 & 0.99578 & 79.500 & 7.799 & 0.99569 & 79.681 & 7.742 & 0.99572 & 79.651 \\
\hline USA & 6.305 & 0.99280 & 76.700 & 8.115 & 0.99468 & 78.676 & 7.527 & 0.99479 & 78.354 \\
\hline
\end{tabular}

Table 7. Targets for inefficient DMUs computed by different DEA approaches 


\begin{tabular}{lcccc}
\hline DMU & CP-DEA & RDM & MEA & $\begin{array}{c}\text { SBM, PBM } \\
\text { Hampf and Krüger (2015) }\end{array}$ \\
\hline Australia & $\mathbf{0 . 0 4 2}$ & 0.156 & 0.162 & 0.114 \\
Austria & $\mathbf{0 . 6 6 4}$ & 1.430 & 1.523 & 1.733 \\
Belgium & $\mathbf{0 . 4 1 2}$ & 1.009 & 1.010 & 0.804 \\
France & $\mathbf{0 . 1 5 3}$ & 0.643 & 0.572 & 0.345 \\
Germany & $\mathbf{0 . 6 4 2}$ & 1.254 & 1.538 & 1.716 \\
Hungary & $\mathbf{0 . 7 9 9}$ & 2.084 & 2.109 & 1.962 \\
Italy & $\mathbf{0 . 4 4 4}$ & 0.891 & 0.923 & 0.738 \\
Netherlands & $\mathbf{0 . 4 5 9}$ & 0.979 & 0.996 & 0.824 \\
New Zealand & $\mathbf{0 . 1 2 5}$ & 0.321 & 0.318 & 0.248 \\
Poland & $\mathbf{0 . 4 4 9}$ & 0.884 & 0.916 & 0.815 \\
Portugal & $\mathbf{0 . 5 0 9}$ & 1.269 & 1.249 & 1.499 \\
Switzerland & $\mathbf{0 . 0 7 3}$ & 0.340 & 0.312 & 0.181 \\
USA & $\mathbf{0 . 7 6 6}$ & 1.819 & 1.554 & 1.987 \\
\hline
\end{tabular}

Table $8 . l_{1}$ distance from the different targets to the ideal point

\begin{tabular}{lcccc}
\hline DMU & CP-DEA & RDM & MEA & $\begin{array}{c}\text { SBM, PBM } \\
\text { Hampf and Krüger (2015) }\end{array}$ \\
\hline Australia & $\mathbf{0 . 0 3 9}$ & 0.112 & 0.120 & 0.114 \\
Austria & $\mathbf{0 . 3 9 7}$ & 1.119 & 1.082 & 1.732 \\
Belgium & $\mathbf{0 . 2 7 7}$ & 0.743 & 0.746 & 0.803 \\
France & $\mathbf{0 . 1 1 9}$ & 0.577 & 0.466 & 0.345 \\
Germany & $\mathbf{0 . 3 8 2}$ & 0.924 & 1.155 & 1.715 \\
Hungary & $\mathbf{0 . 5 7 8}$ & 1.707 & 1.671 & 1.958 \\
Italy & $\mathbf{0 . 2 8 0}$ & 0.631 & 0.668 & 0.736 \\
Netherlands & $\mathbf{0 . 2 9 6}$ & 0.695 & 0.717 & 0.823 \\
New Zealand & $\mathbf{0 . 0 8 9}$ & 0.235 & 0.231 & 0.247 \\
Poland & $\mathbf{0 . 3 2 9}$ & 0.683 & 0.662 & 0.811 \\
Portugal & $\mathbf{0 . 3 1 8}$ & 0.938 & 0.906 & 1.498 \\
Switzerland & $\mathbf{0 . 0 6 2}$ & 0.340 & 0.284 & 0.181 \\
USA & $\mathbf{0 . 5 3 1}$ & 1.810 & 1.267 & 1.985 \\
\hline
\end{tabular}

Table $9 . l_{2}$ distance from the different targets to the ideal point 


\begin{tabular}{lcccc}
\hline DMU & CP-DEA & RDM & MEA & $\begin{array}{c}\text { SBM, PBM } \\
\text { Hampf and Krüger (2015) }\end{array}$ \\
\hline Australia & $\mathbf{0 . 0 3 0}$ & 0.092 & 0.105 & 0.114 \\
Austria & $\mathbf{0 . 2 6 3}$ & 1.054 & 0.838 & 1.732 \\
Belgium & $\mathbf{0 . 1 9 7}$ & 0.652 & 0.657 & 0.803 \\
France & $\mathbf{0 . 0 8 9}$ & 0.573 & 0.450 & 0.345 \\
Germany & $\mathbf{0 . 2 5 2}$ & 0.811 & 1.044 & 1.715 \\
Hungary & $\mathbf{0 . 3 5 0}$ & 1.652 & 1.589 & 1.958 \\
Italy & $\mathbf{0 . 1 8 4}$ & 0.467 & 0.563 & 0.736 \\
Netherlands & $\mathbf{0 . 2 0 2}$ & 0.533 & 0.592 & 0.823 \\
New Zealand & $\mathbf{0 . 0 6 3}$ & 0.203 & 0.195 & 0.247 \\
Poland & $\mathbf{0 . 2 0 0}$ & 0.637 & 0.558 & 0.811 \\
Portugal & $\mathbf{0 . 2 2 3}$ & 0.829 & 0.768 & 1.498 \\
Switzerland & $\mathbf{0 . 0 4 8}$ & 0.340 & 0.282 & 0.181 \\
USA & $\mathbf{0 . 3 3 5}$ & 1.810 & 1.223 & 1.985 \\
\hline
\end{tabular}

Table 10. $l_{\infty}$ distance from the different targets to the ideal point 


\begin{tabular}{|c|c|c|c|c|c|c|c|c|}
\hline \multirow{2}{*}{ DMU } & \multicolumn{3}{|c|}{ CP-DEA } & \multirow{2}{*}{ SBM } & \multirow{2}{*}{$\begin{array}{l}\text { Hampf and } \\
\text { Krüger }^{*}\end{array}$} & \multirow{2}{*}{ RDM } & \multirow{2}{*}{ MEA } & \multirow{2}{*}{ PBM } \\
\hline & $p=1$ & $p=2$ & $p=\infty$ & & & & & \\
\hline Australia & 0.817 & 0.871 & 0.897 & 0.975 & 0.026 & 0.806 & 0.807 & 0.996 \\
\hline Austria & 0.526 & 0.618 & 0.685 & 0.828 & 0.172 & 0.758 & 0.669 & 0.969 \\
\hline Belgium & 0.522 & 0.604 & 0.639 & 0.830 & 0.170 & 0.681 & 0.680 & 0.969 \\
\hline France & 0.597 & 0.624 & 0.640 & 0.866 & 0.134 & 0.849 & 0.853 & 0.976 \\
\hline Germany & 0.332 & 0.373 & 0.385 & 0.657 & 0.343 & 0.576 & 0.507 & 0.932 \\
\hline Hungary & 0.257 & 0.320 & 0.332 & 0.763 & 0.275 & 0.605 & 0.589 & 0.951 \\
\hline Italy & 0.555 & 0.658 & 0.713 & 0.862 & 0.139 & 0.655 & 0.639 & 0.975 \\
\hline Netherlands & 0.604 & 0.676 & 0.707 & 0.859 & 0.141 & 0.753 & 0.741 & 0.975 \\
\hline New Zealand & 0.704 & 0.782 & 0.819 & 0.950 & 0.050 & 0.812 & 0.812 & 0.991 \\
\hline Poland & 0.383 & 0.479 & 0.506 & 0.867 & 0.151 & 0.748 & 0.728 & 0.974 \\
\hline Portugal & 0.423 & 0.517 & 0.559 & 0.815 & 0.195 & 0.717 & 0.710 & 0.965 \\
\hline Switzerland & 0.385 & 0.401 & 0.405 & 0.715 & 0.285 & 0.685 & 0.684 & 0.946 \\
\hline USA & 0.198 & 0.227 & 0.227 & 0.462 & 0.538 & 0.472 & 0.469 & 0.879 \\
\hline
\end{tabular}

* Inefficiency scores

Table 11. Efficiency scores computed by different DEA approaches

\begin{tabular}{|c|c|c|c|c|c|c|c|c|}
\hline & $\begin{array}{c}\text { CP-DEA } \\
p=1\end{array}$ & $\begin{array}{c}\text { CP-DEA } \\
p=2\end{array}$ & $\begin{array}{c}\text { CP-DEA } \\
p=\infty\end{array}$ & SBM & $\begin{array}{c}\text { Hampf and } \\
\text { Krüger }\end{array}$ & RDM & MEA & PBM \\
\hline CP-DEA $p=1$ & 1.000 & 0.989 & 0.967 & 0.802 & 0.901 & 0.808 & 0.769 & 0.912 \\
\hline CP-DEA $p=2$ & & 1.000 & 0.989 & 0.841 & 0.923 & 0.769 & 0.731 & 0.931 \\
\hline CP-DEA $p=\infty$ & & & 1.000 & 0.824 & 0.901 & 0.725 & 0.654 & 0.906 \\
\hline SBM & & & & 1.000 & 0.967 & 0.775 & 0.797 & 0.964 \\
\hline Hampf and Krüger & & & & & 1.000 & 0.786 & 0.797 & 0.997 \\
\hline $\mathrm{RDM}$ & & & & & & 1.000 & 0.918 & 0.815 \\
\hline MEA & & & & & & & 1.000 & 0.813 \\
\hline PBM & & & & & & & & 1.000 \\
\hline
\end{tabular}

Table 12. Spearman's rank correlation coefficients between the different DEA approaches 


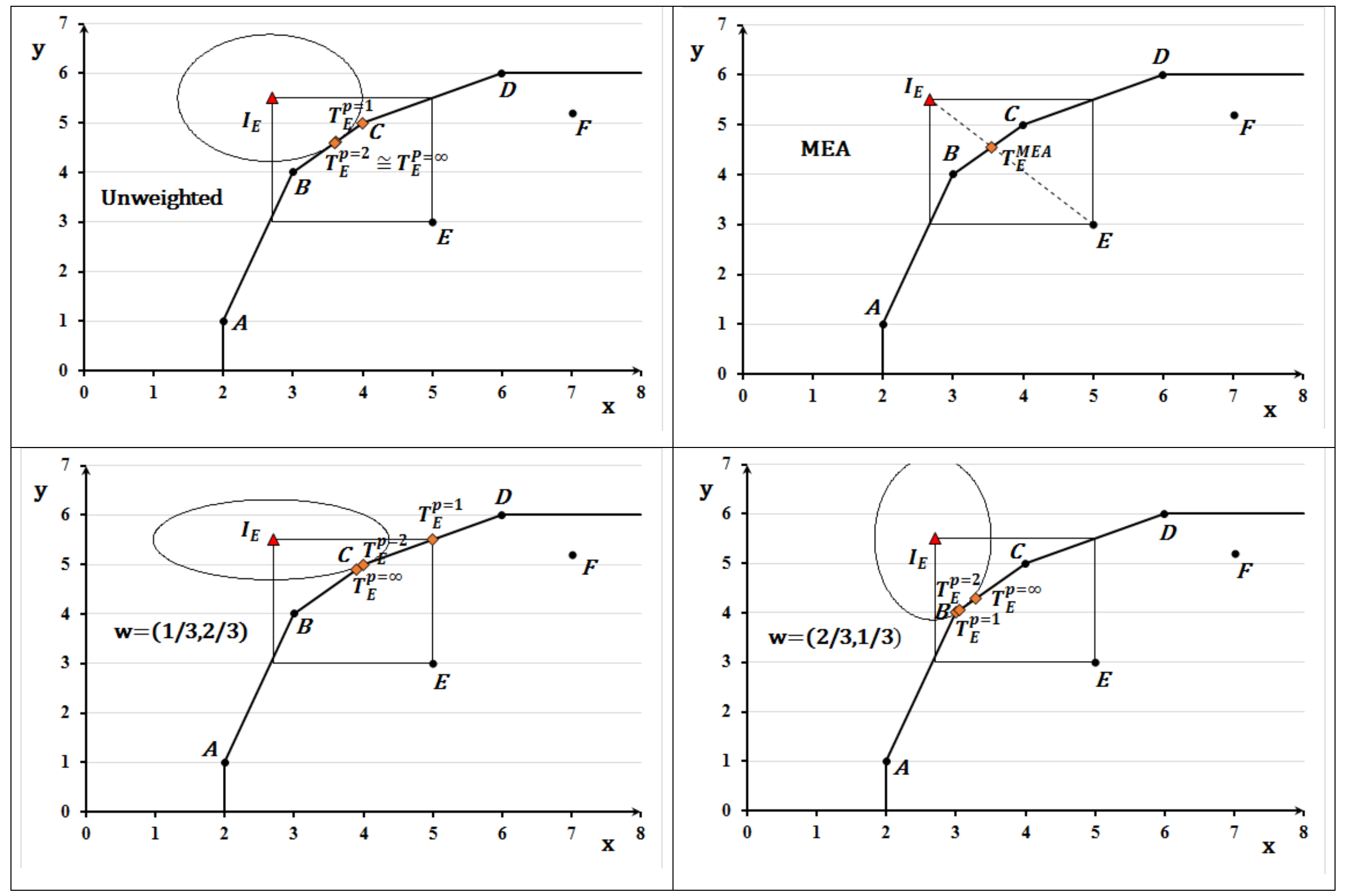

Figure 1. Visualization of the CP-DEA targets for unit E 

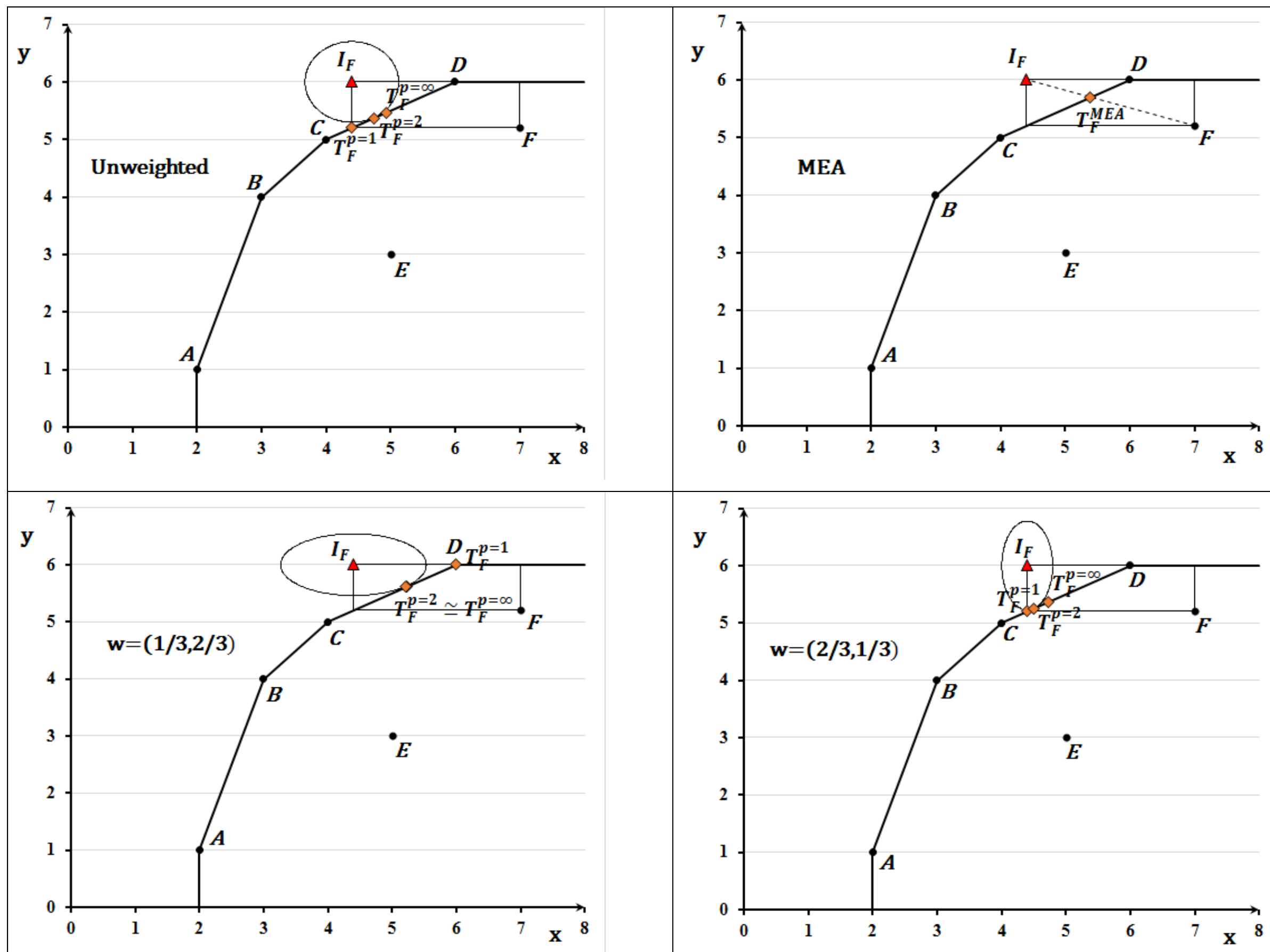

Figure 2. Visualization of the CP-DEA targets for unit $\mathrm{F}$ 


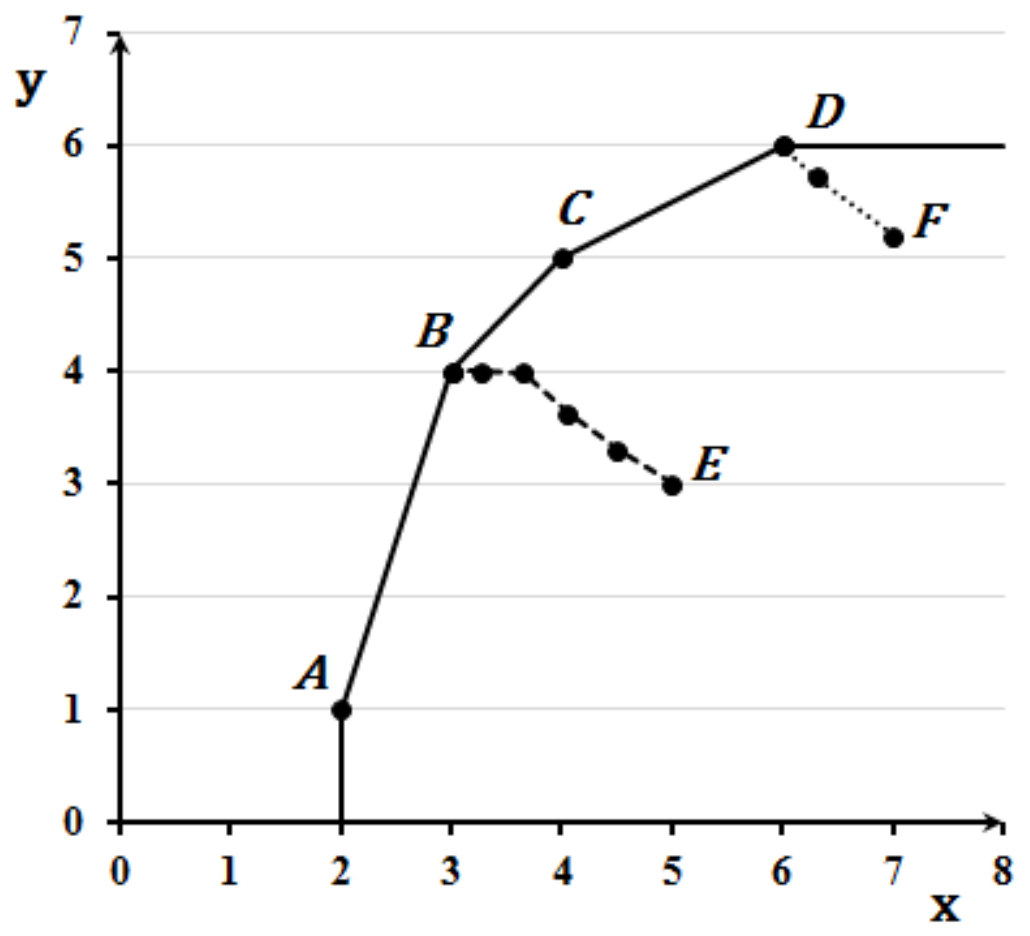

Figure 3. Visualization of the sequence of targets computed by Dehnokhalaji and Soltani (2019) for units E and F 


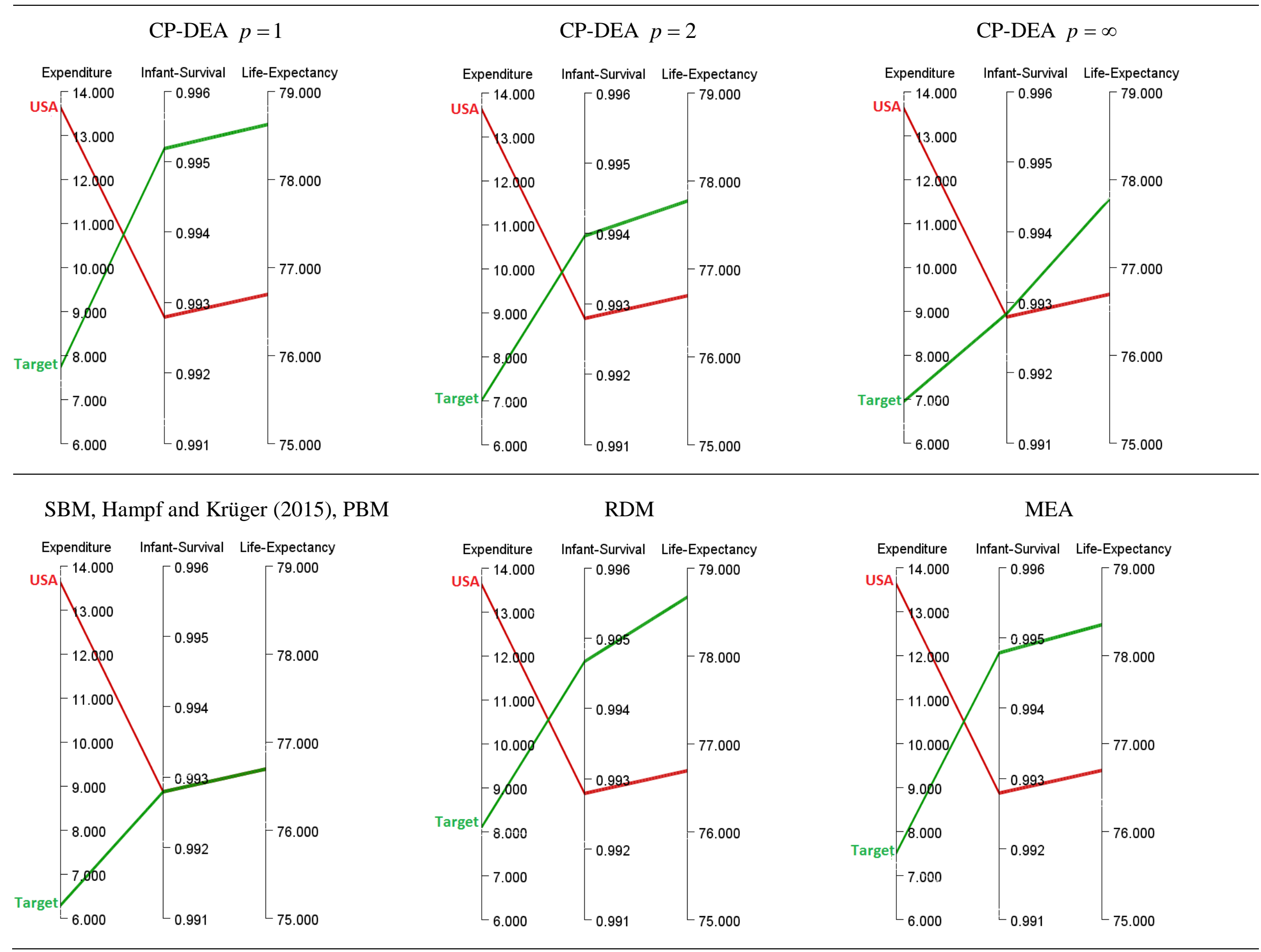

Figure 4. Parallel coordinates representation of the computed targets for USA 